$$
\begin{aligned}
& \text { الأرق للى عينات مصرية من طلاب الجامعة والموظفين }
\end{aligned}
$$

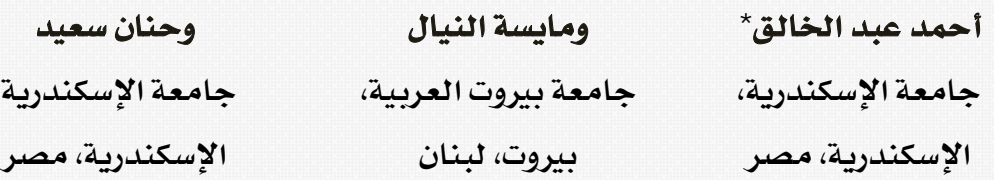

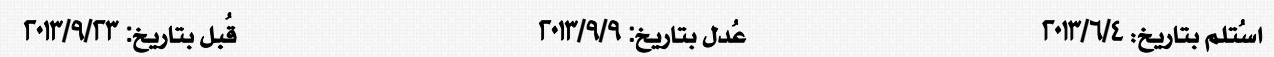

$$
\begin{aligned}
& \text { هدفت هذه الدراسة إلى تحديد معدلات انتشار الأرق، والفروق بين الجنسين، وبين مجموعتين عمريتين، وبيان البنية العاملية للمقياس العربي }
\end{aligned}
$$

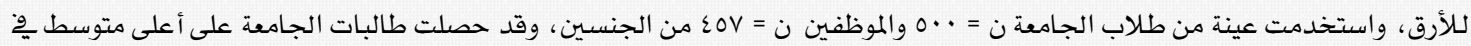

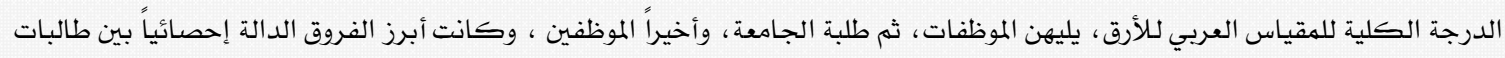

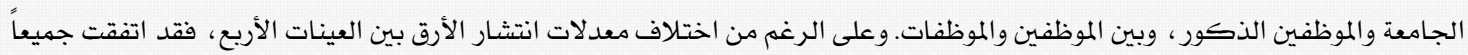

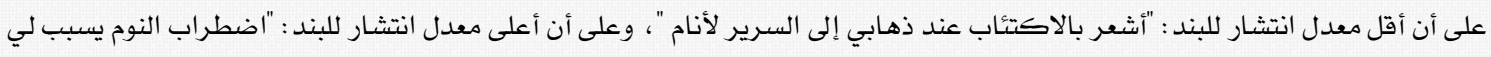

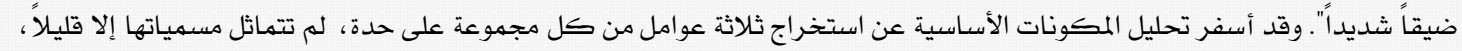

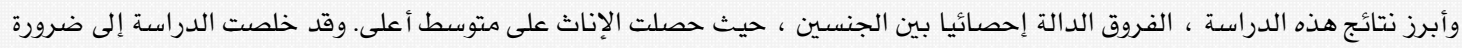

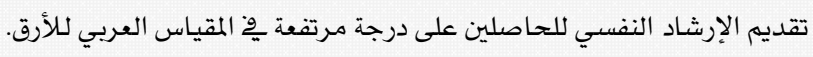

$$
\begin{aligned}
& \text { كلمات مفتاحية: الأرق، المقياس العربي لللأرق، طلبة الجامعات، الموظفون، مصر. }
\end{aligned}
$$

\title{
Insomnia among Egyptian Samples of University Students and Employees
}
A hmed Abdel-Khalek*
Alexandria University,
Alexandria, Egypt
Maysa al Nyal
Hanan Saeed
Beirut Arab University, Beirut,
Lebanon
Alexandria University, Alexandria, Egypt

The aim of this study was to estimate the prevalence of insomnia, differences between males and females, and between two age groups, and to explore the factorial structure of the A rabic Scale of Insomnia (ASI). Samples of university students $(n=500)$ and employees $(n=457)$ of both sexes were recruited. Female university students obtained the highest mean total score on the ASI, followed by female employees, male university students, and finally male employees. The salient significant differences were between female students and male employees and between male and female employees. Despite the differences in the prevalence rate of insomnia between the four groups, they all agreed on that the least prevalence rate was for the item: "I feel depressed when it is time for me to go to bed, whereas the highest prevalence rate was for the item: "My interrupted sleep annoys me." Principle components analysis yielded three factors for each group. Most of their names were not identical. The most salient finding of this study was the statistically significant sex differences in insomnia in favor of women. It was concluded that is it important to introduce counseling for those who obtained high scores on the ASI.

Keywords: insomnia, the A rabic Scale of Insomnia (ASI ), university students, employees, Egypt.

*aabsel-khalek@hotmail.com 


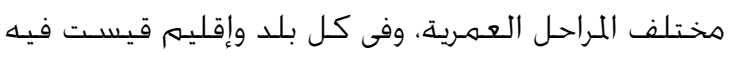

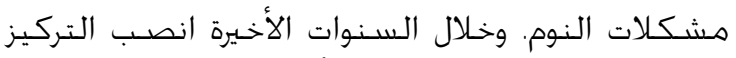

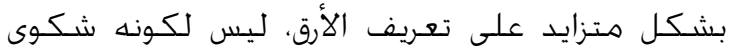

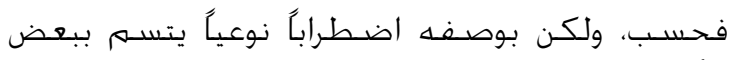

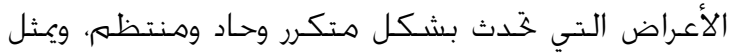

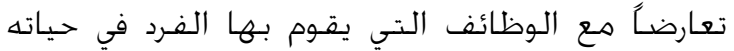

اليومية (Buysse, 2008).

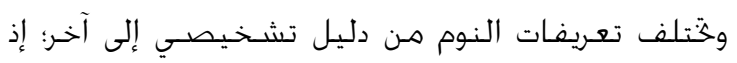

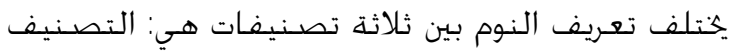

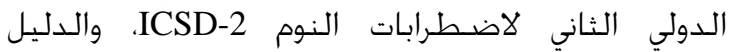

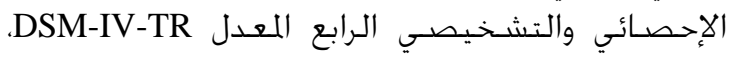

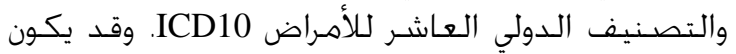

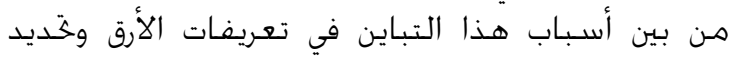

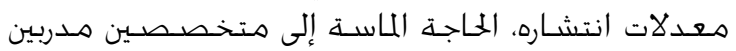

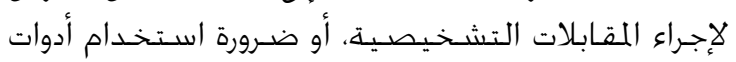

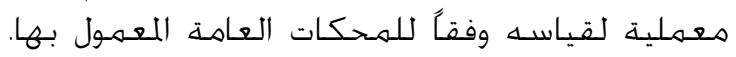

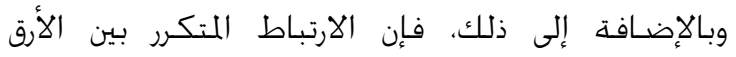

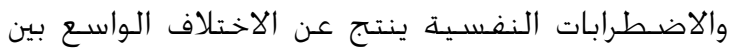

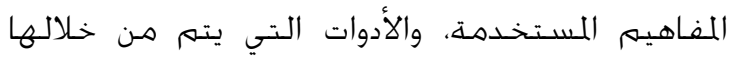
قياس الأرق (www.intechopen.com).

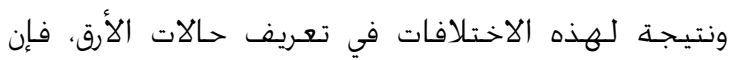

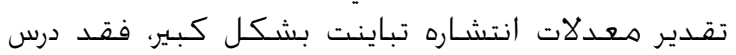
بالاسين، ونورداس، ونيلسين، وهافيك، وكال، وجونسين. Pallesen, Nordhus, Nielson, ) وسكيوتسكيفيفت ونان في (Havik, Kvale, Johnsen, \& Skjøtskift, 2001 النرويج، مدي انتشار الأرق لدي عينات من الراشدين

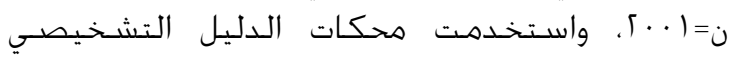

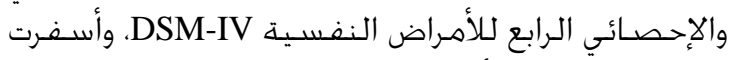

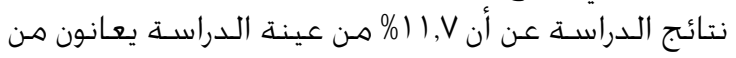

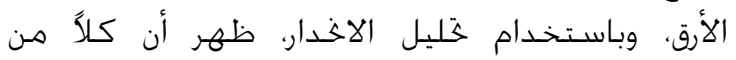

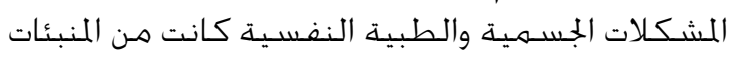

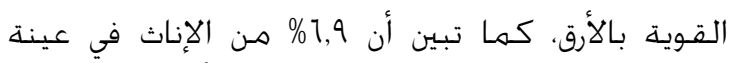

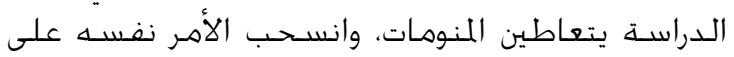

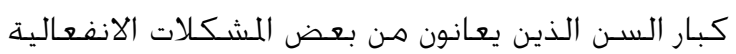

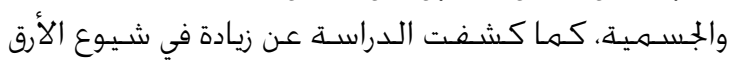

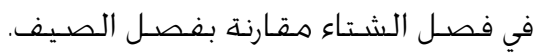

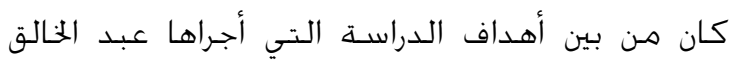
بيان معدلات انتشار الأرق الجنان (Abdel-Khalek, 2004)

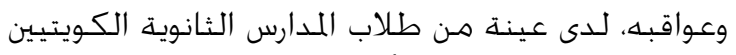

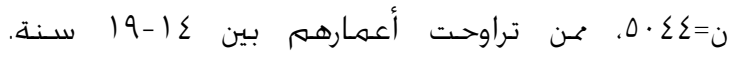

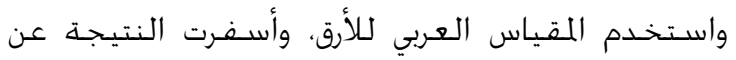

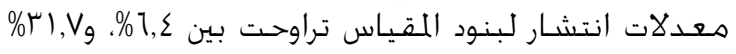

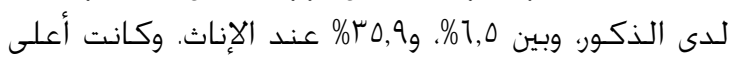

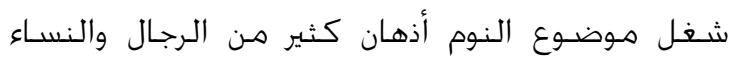

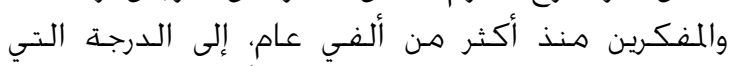

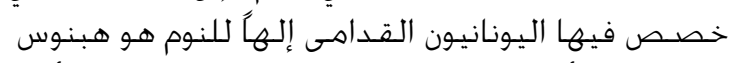
Hipnos

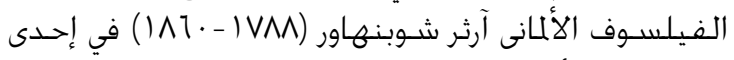

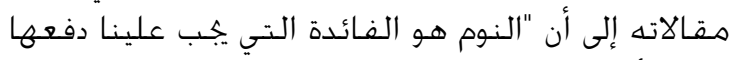

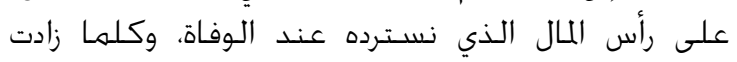

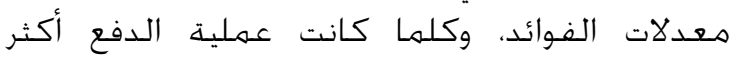

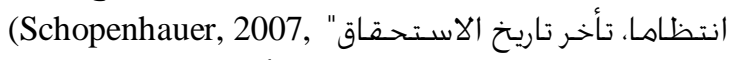

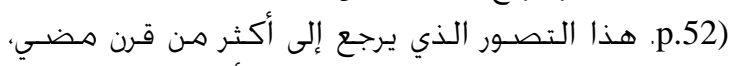

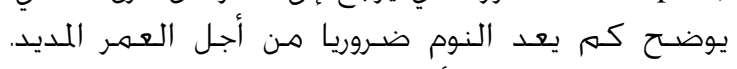

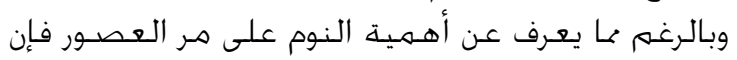

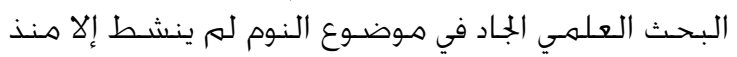

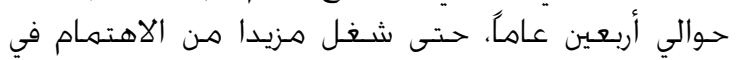

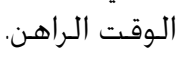

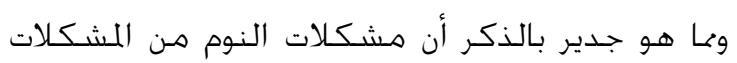

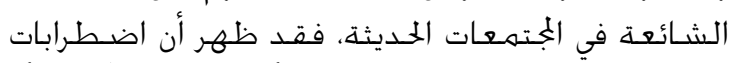

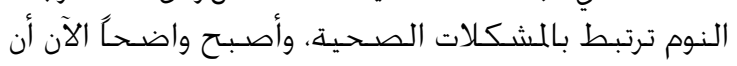

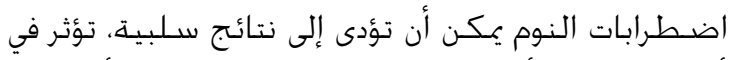

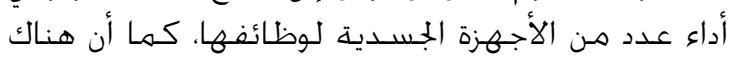

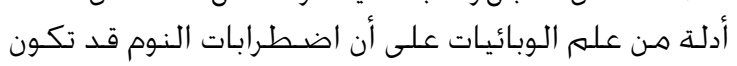

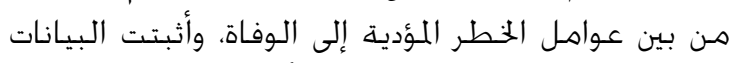

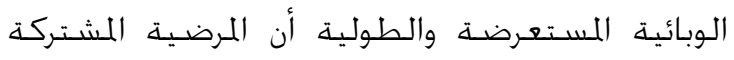
Comorbidity

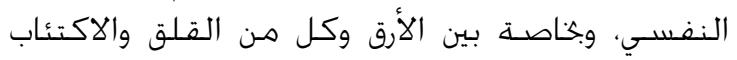

.(Abdel-Khalek, 2008)

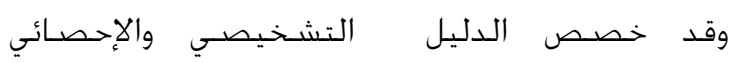
للاضطرابات النفسية الرابع العـدل (DSM-IV-TR)

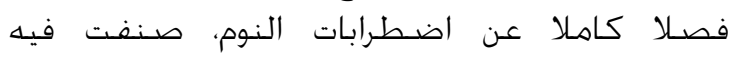
اضطرابات النوم في فئتين أسـاسيتين: اضطرات النرابات أولية

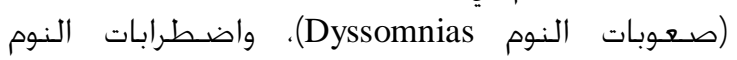

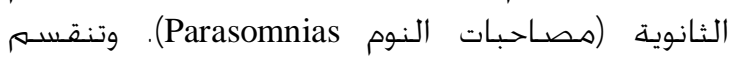

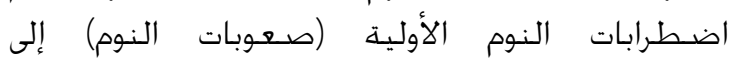

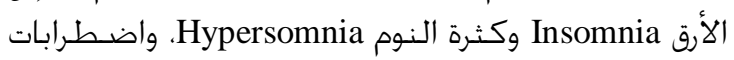
جدول النوم/اليقظة Sleep-wake schedule disorder. أها فيما يتعلق باضط النورابات النوم الثانوية (مصاحبات

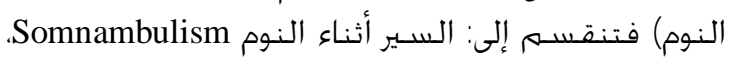

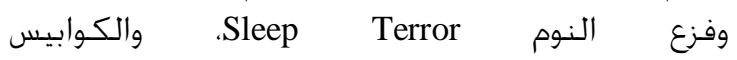
الليلية APA, 2000, pp.567-661) Nightmares).

وتضطلع هذه الدراسـة بفحص موضوع الأرق لدي

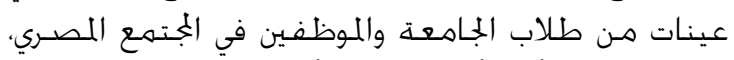

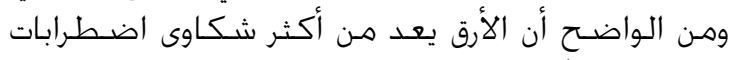

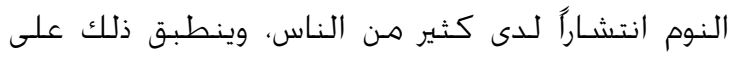




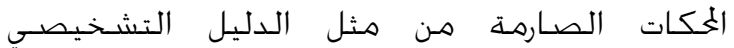

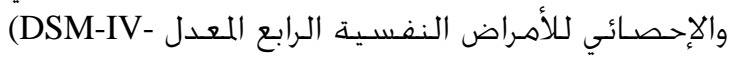

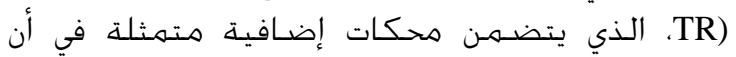

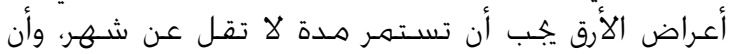

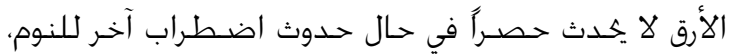

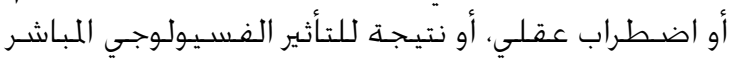

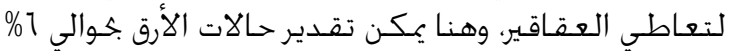

(Roth, 2007)

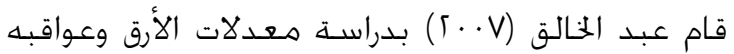

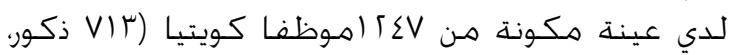

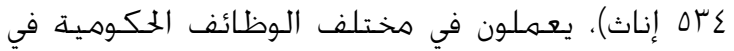

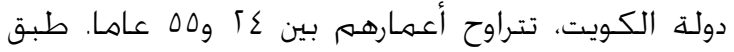

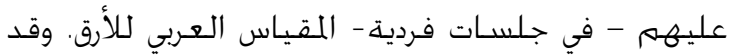

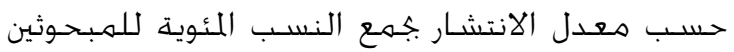
الذين يشكون من الأرق في الشهر الأخير في البديلين:

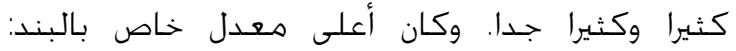

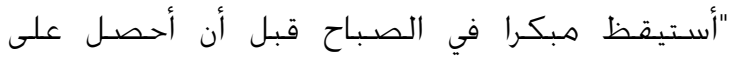

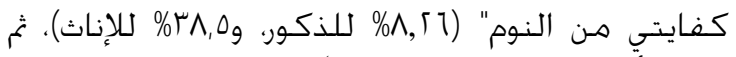

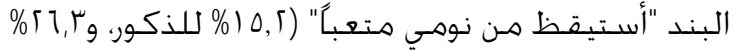

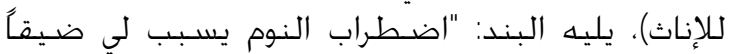

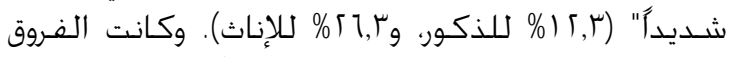

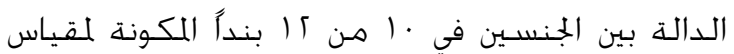

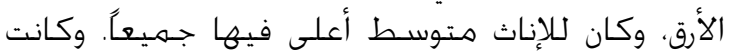

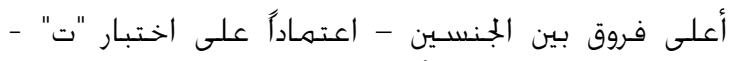

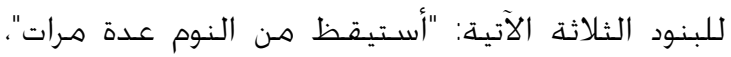

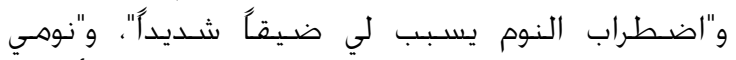
متقطع وهضطرب" على التوالي (متوسط الإناث أعلى).

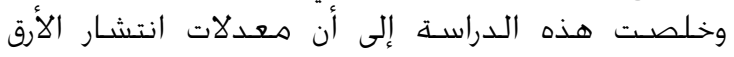

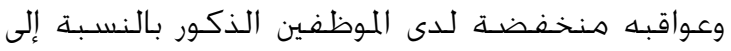

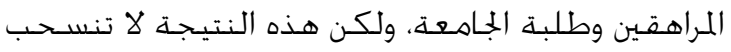

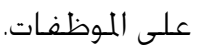

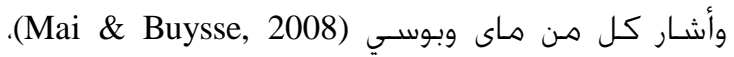

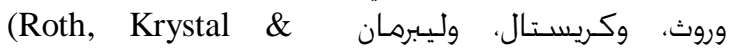

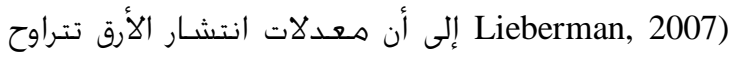

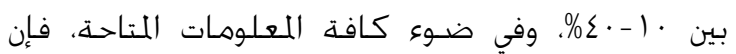

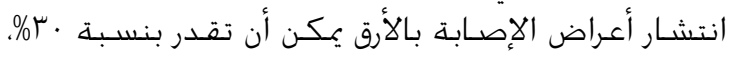

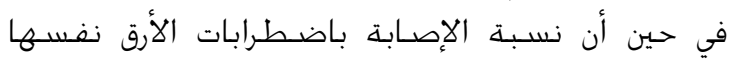

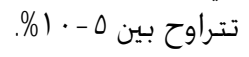

قام كل من سينج وونج (Sing \& Wong, 2010) بدراسـة

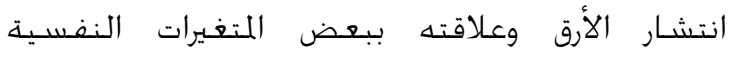

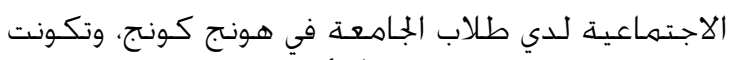

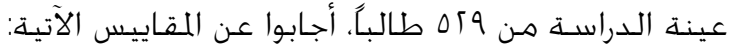

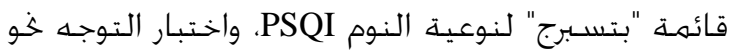

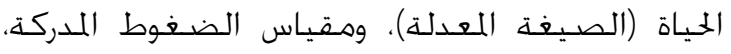
وقائمة "بيك" للاكتئاب، وأسئلة أخرى تقيس بعض الخض

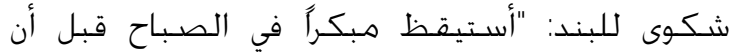

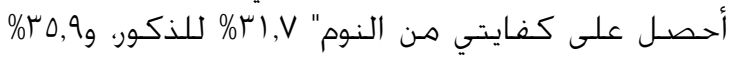

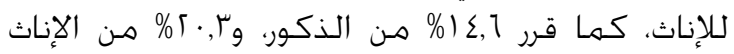

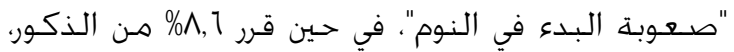

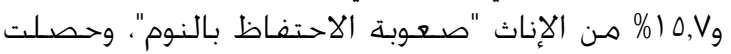

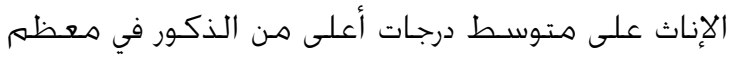

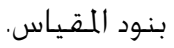

درس عبد الخالق (Abdel-Khalek, 2006) عينة كويتية

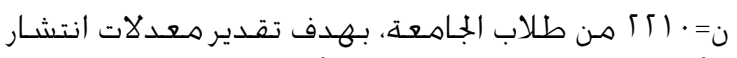

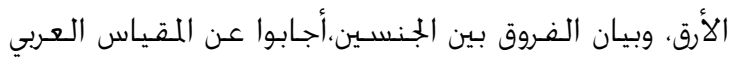

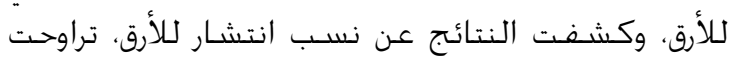

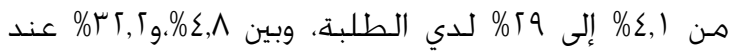

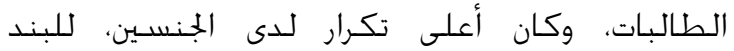

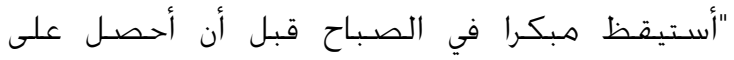

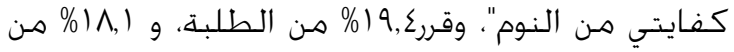

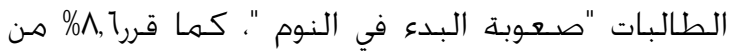

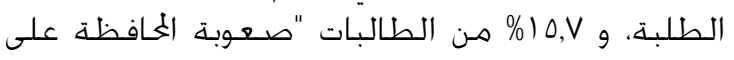
النوم "، وكان متوسط الطالبات الطات أعلى من الطلبة في لطي ثلاثـة بـنود.

وفي دراسـة أجريت في اليابان، لفحص معدلاتلات انتشـار الأرق لدى مجموعات عمرية مختلفة، قار كام كانيتا وأوهيدا

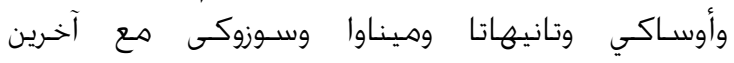
Kaneita, Ohida, Osaki, Tanihata, Minowa, Suzuki, ) بدراسـة على عينات من المراهقين باستخـدام (et al. 2006 المنهج المستعرض، حيث شـملت عينة الدراسـة تلاميذ المراسئ

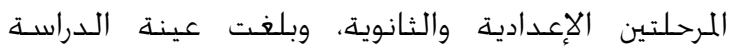

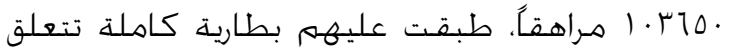

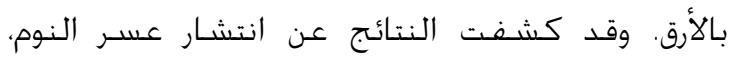

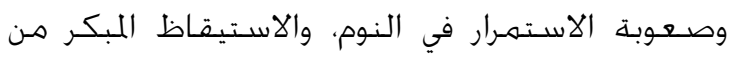

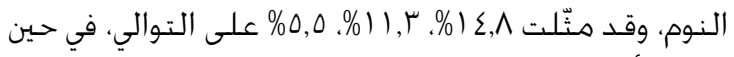

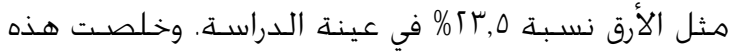

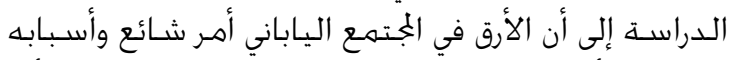

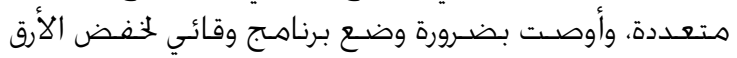
لدى المراهقين اليابانيين.

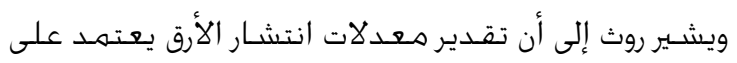

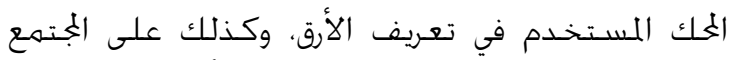

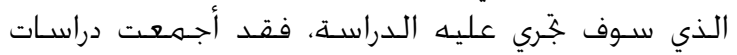

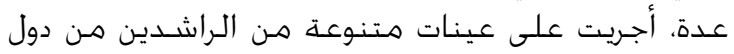

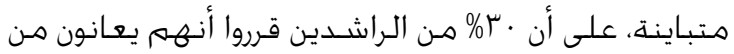

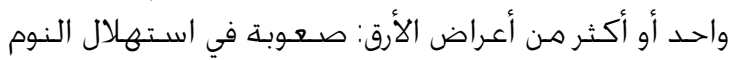

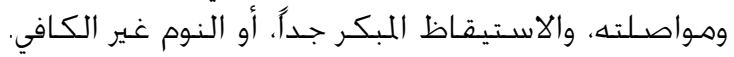

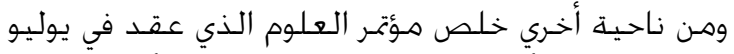

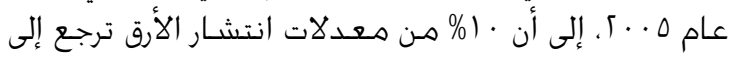

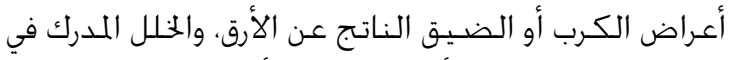

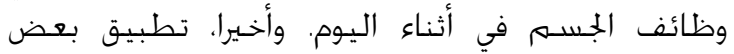


وقد عقدت المعاهد القومية للحالة الصحية مؤمتراً بعنوان: "هظاهر الأرق المزهن لدى الراشـين لحإين وإدارته" Manifestations and management of chronic insomnia in adults

البحثية للأرق Research Diagnostic Criteria for والنسخة الثانية لتصنيف International Classification of اضطرابات النوم Sleep Disorders, Second Edition (ICSD-2) واعتمدت المنظور الواسع للأرق بوصفه اضطرابًا

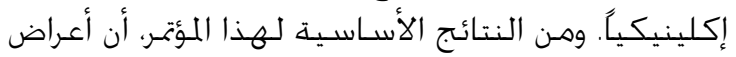

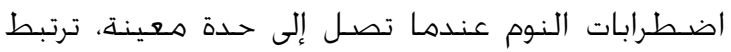

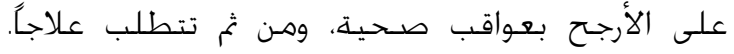

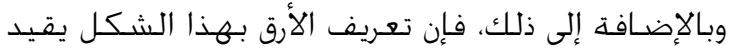

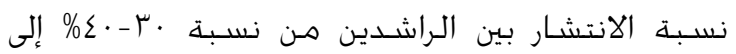

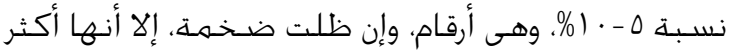

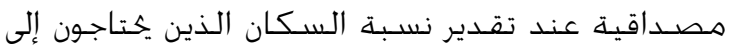

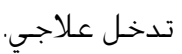
وأوضـح أوهايون (Ohayon, 1997) أن تقديرات انتشـار

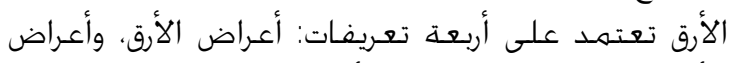

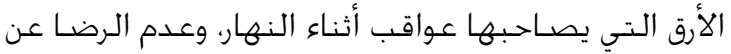

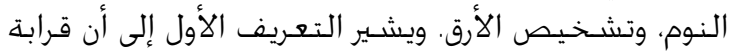

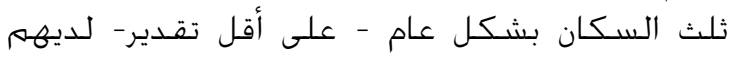

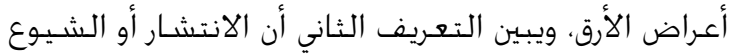

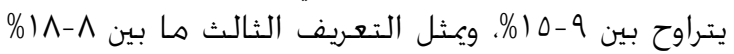

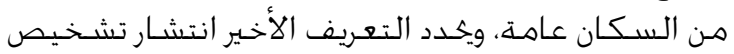

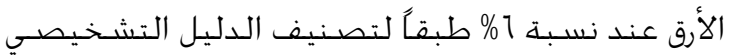

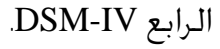

وبالرغم من هذه الغماولات الجادة مسن قبل الباحثين المهتمين

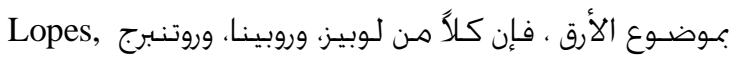

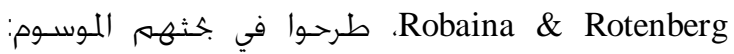

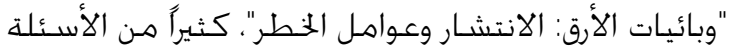

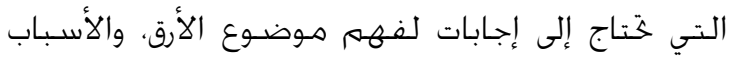

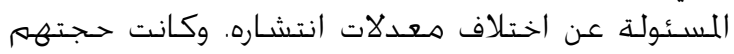

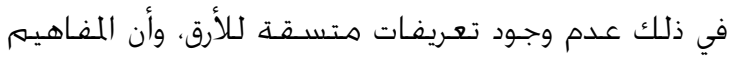

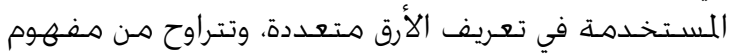

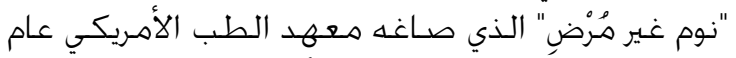

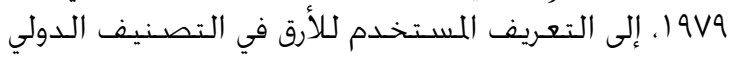

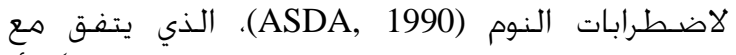

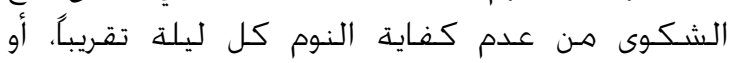
الشعور بالتعب بعد فترة النوم المعتادة.

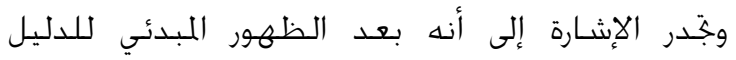

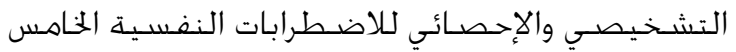

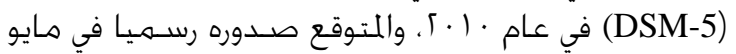

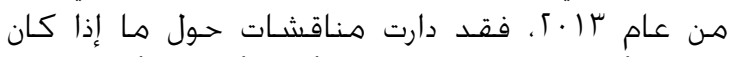
ينبغي أن يستبدل بالفئتين: الأرق الأولي، والأرق الثانوي ما إنان

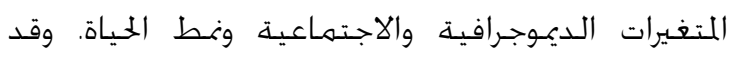

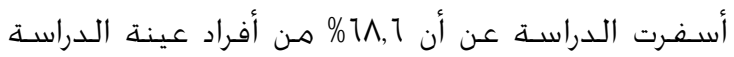

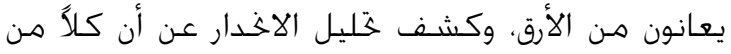
الضغوط، والاكتئاب من منبئات الأرق.

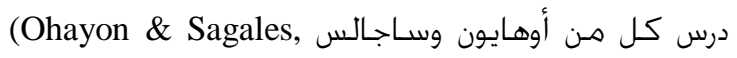
(2010 هدى انتشار الأرق في الجمتهع الأسباني، فأجريا

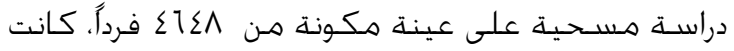

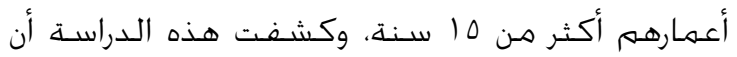

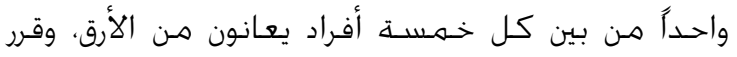

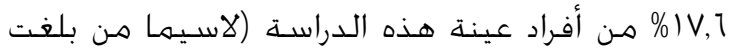

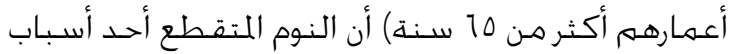

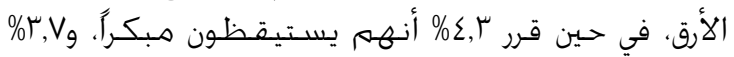

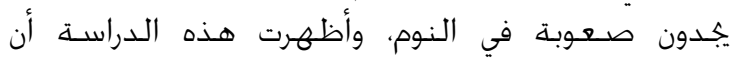

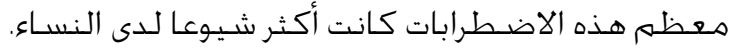
وقد هدفت دراسـة بكر وأبو العز وعبد العزيز وخاطر وفهيم \& Bakr, Abou El Ezz, Abd Elaziz, Khater, إلى فحص مدى انتشار الأرق لدى عينة Fahim, 2011)

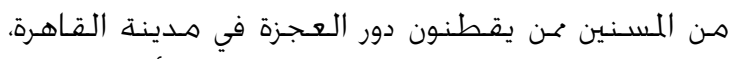

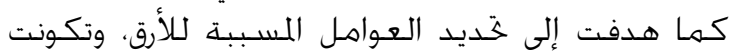

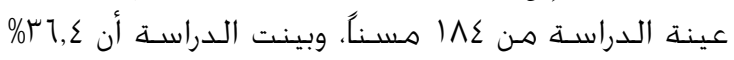

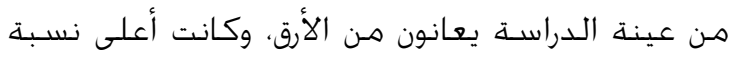
للأرق لدى الذكور والمتزوجين منهمه.

وفي الصين، أجرى كل هن ونج وفيلدينج (Wong \& مراسـة على ( Fielding, 2011)

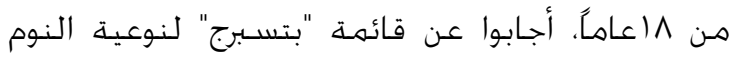

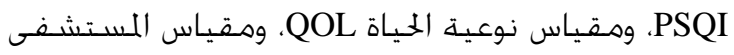

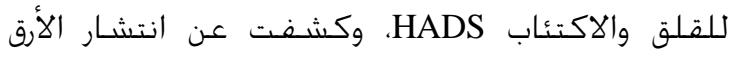

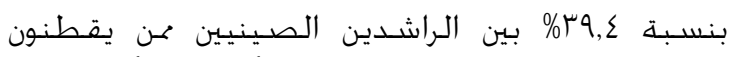
مدينة هونج كونج، وكان يصاحب أعراض الأرق لديهم

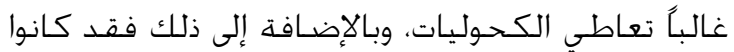

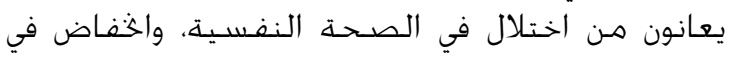

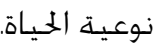

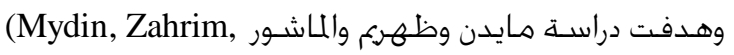
( Almashor, 2012) إلى ثخديد العلاقة بين العوامل

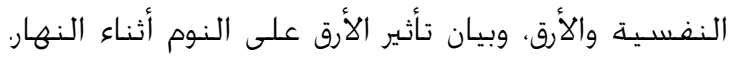

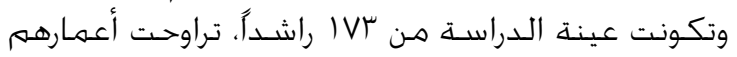

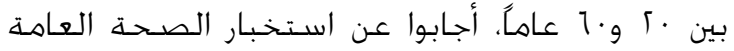

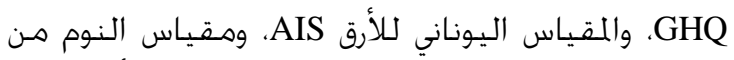

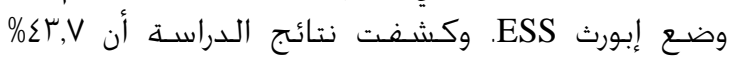

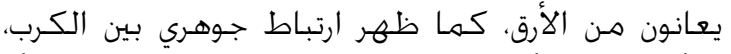

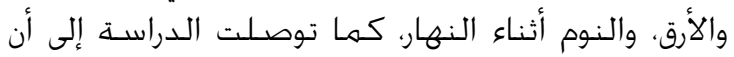

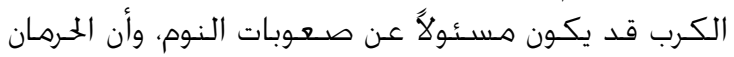
من النوم يؤدى إلى الرغبة في النوم أثناء النهار. 
ينامون بشكل طبيعي وجيد من ناحية، وهرضى الأرق أخرق

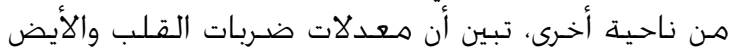

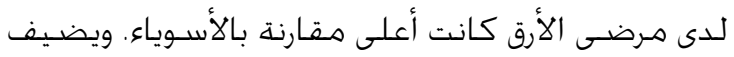

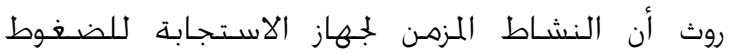

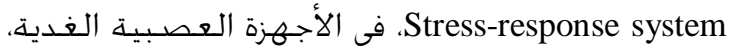

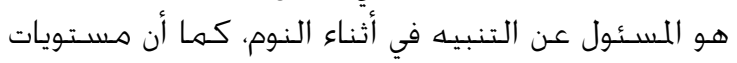

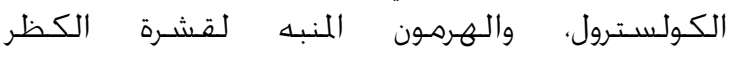
Adrenocorticotrophic

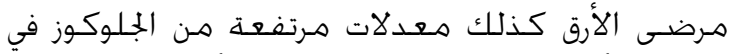

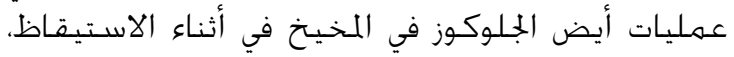

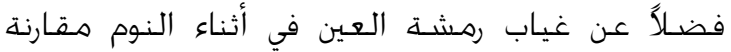

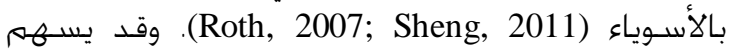

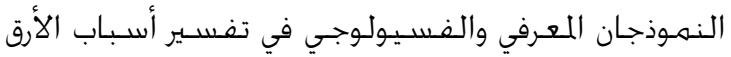

التي تتضمسن التنبيه الزائد، كما أنهما قد في يتكاملان.

أها النموذج المعرفي السـلوكي ( Cognitive-behavioral (model

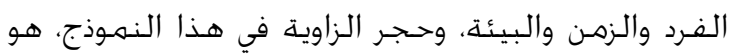

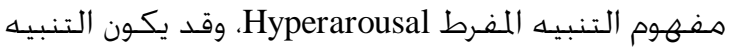

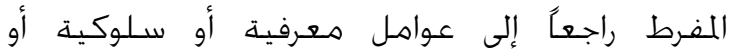

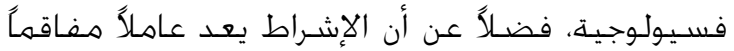

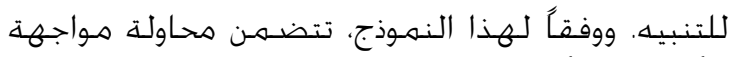

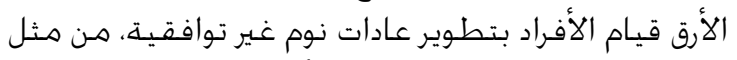

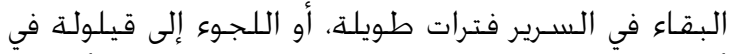

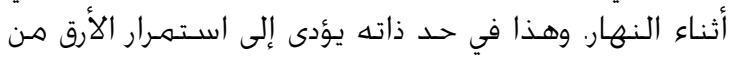

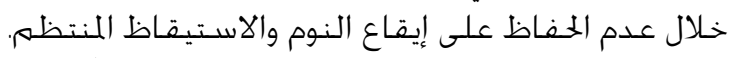

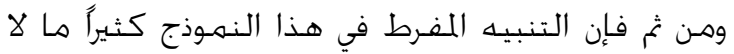

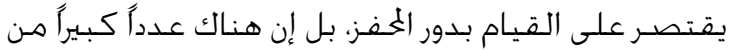

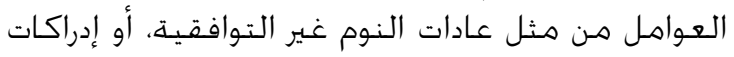

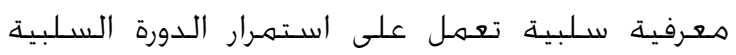
للنوم (Talbot \& Harvey, 2010, p. 43).

عرضت الفقرات السـابقة بعض النماذج الفســرة للأرق.

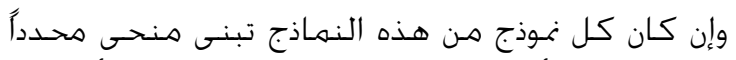

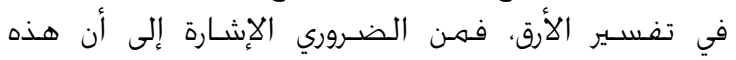

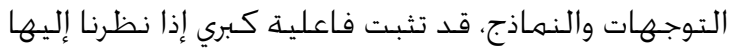

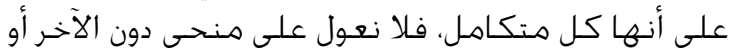

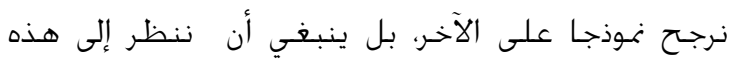

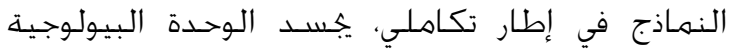

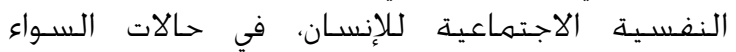

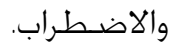

وأجريت دراسـات كثيرة هدفت إلى فحص الفئر الفروق الجـوهرية

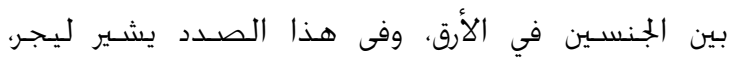

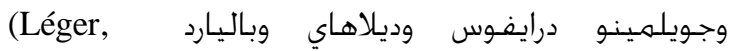
Guilleminault, Dreyfus, Delahaye, \& Paillard,

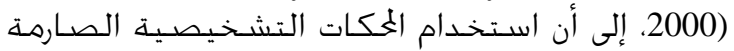

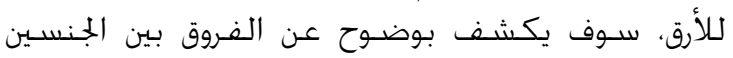

فئة واحدة تسـمي اضطرابات الأرق، وعلى أية حال فإن

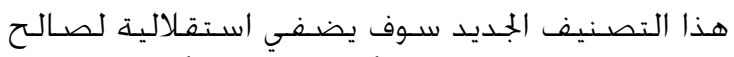

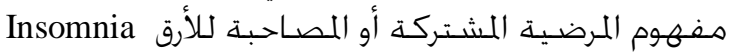
Abe \& Germain, 2012, انظر) comorbidity concept .p. 387

وقد قُدم أكثر من نموذج في محاولة لتفسير أسباب الأرق.

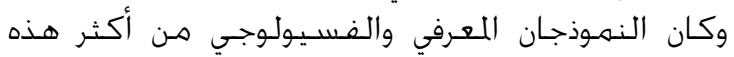

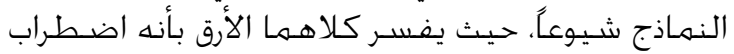

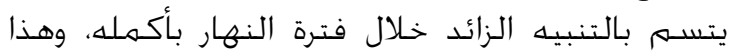

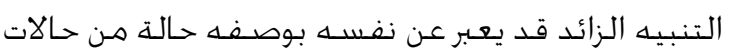
اليقظة المفرطة في أثناء النهار، وصعوبة فئن في استهلال النهال

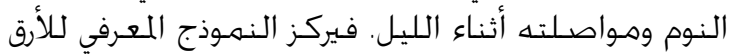

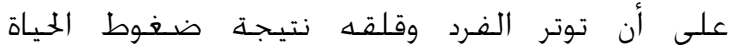

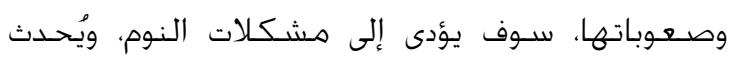

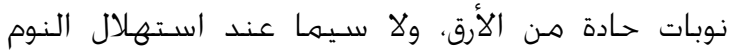

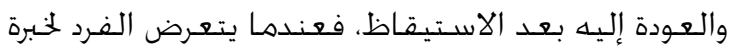

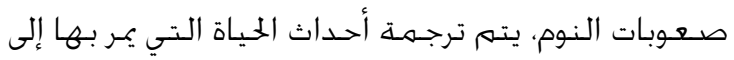

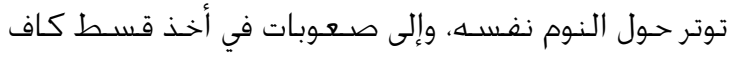

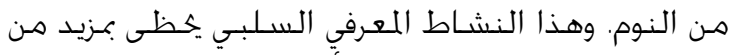

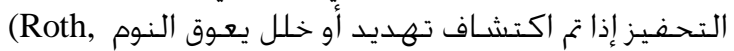

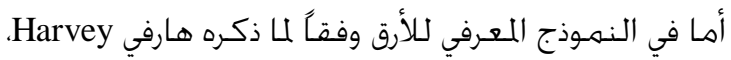

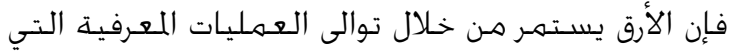

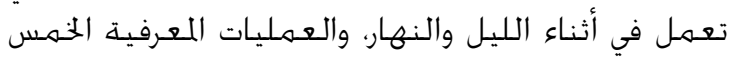

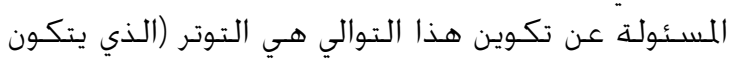

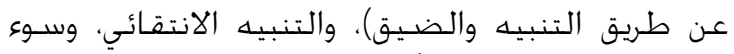

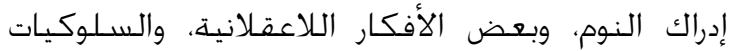

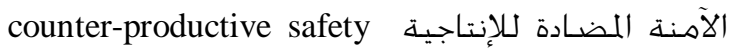
behaviors

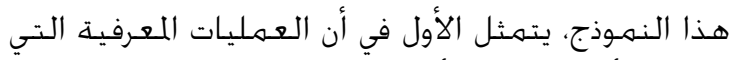

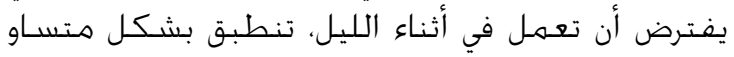

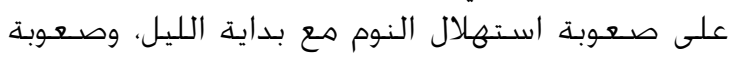

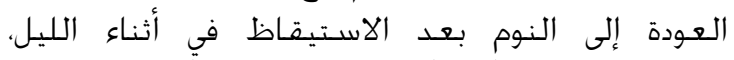

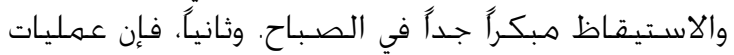

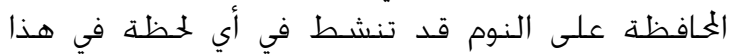

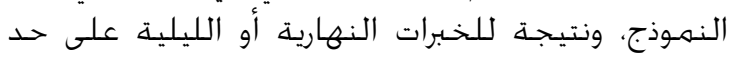
سواء (Abe \& Germain, 2012).

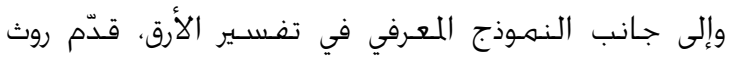

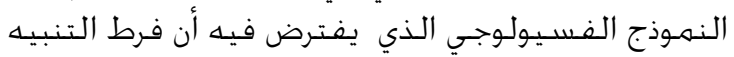

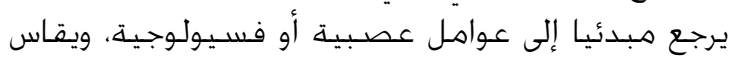

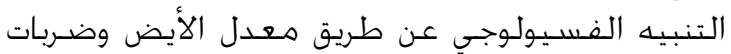

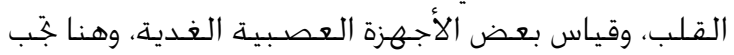

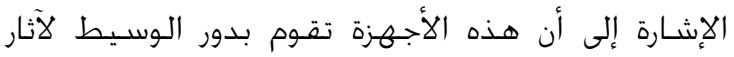

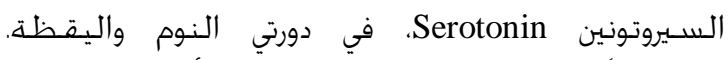
وهصداقاً لذلك. فهندما يُقارن بين الأشخاص الذين 


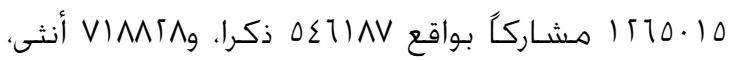
وأسفرت النتائج عن استهداف الإناث للأرق مقار لـارنة

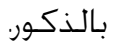

والسئوال المهم هنا: هل يختلف الأرق باختلاف المراحل

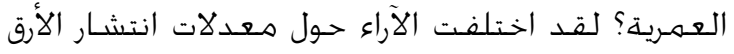

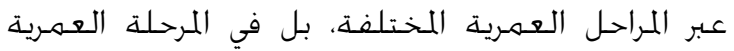

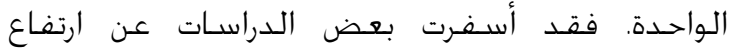

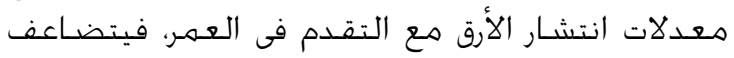

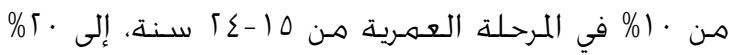

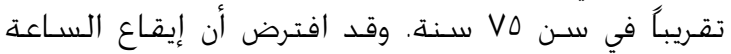

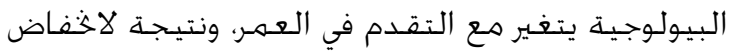

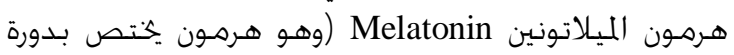

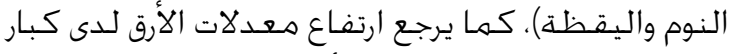

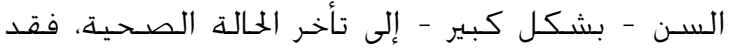

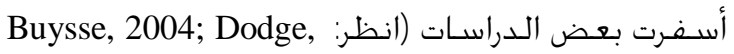

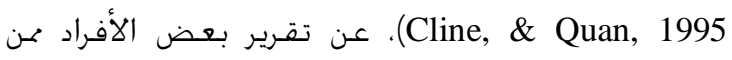

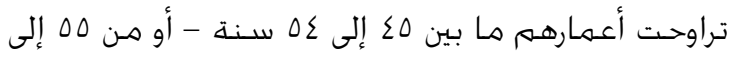

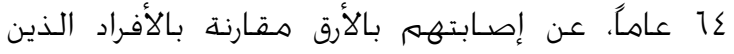

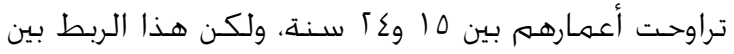

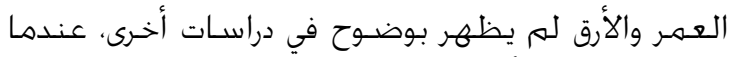

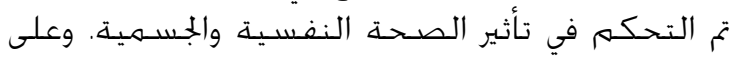

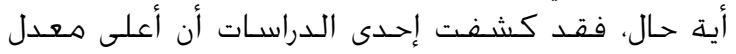

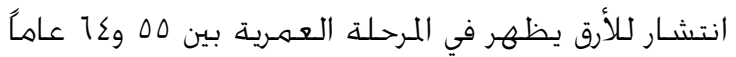

.(Tjepkema, 2005)

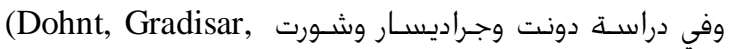
\& Short, 2012)

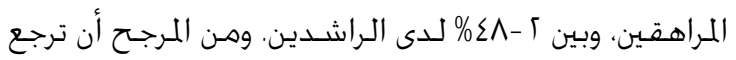

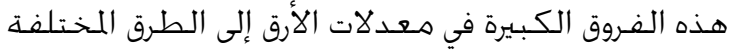

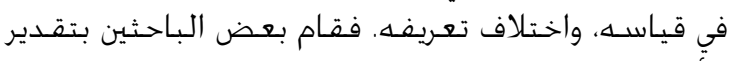

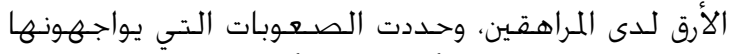

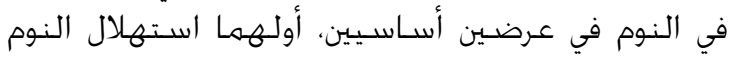

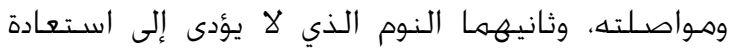
النشاط Non-restorative sleep، وذلك خلال فترة شهر النهر

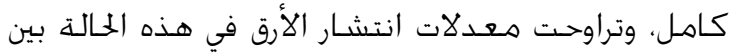

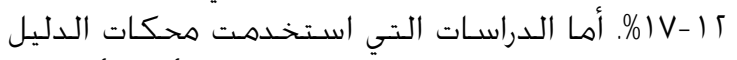

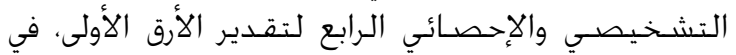

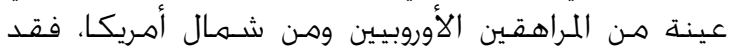

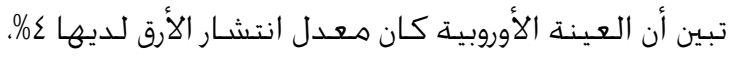
في حين تراوح بين ه - (اله في عينات شـمال أمريكا. وقد هدفت دراسـة زانج ولام ولي وتانج ويو ولي وونج إلى (Zhang, Lam, Li, Tang, Yu, Li, \& Wing, 2012) فحص الفروق في الأرق بين عينة مـن المراهقين وأولياء

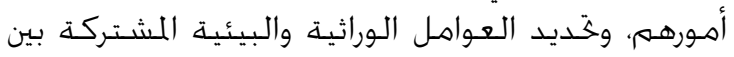
الجنسين والمرتبطة باضطرابات النوم (الأرق، ونوعية لوكتية

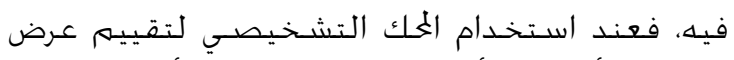

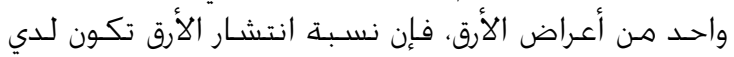

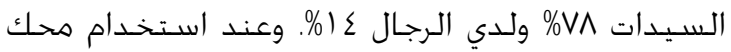

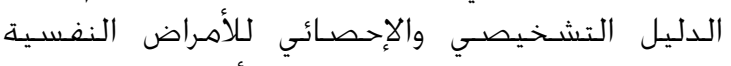

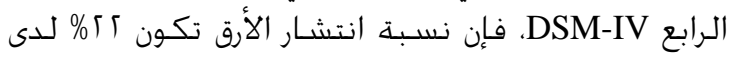

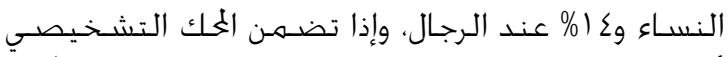

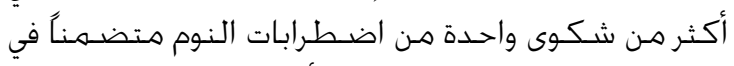

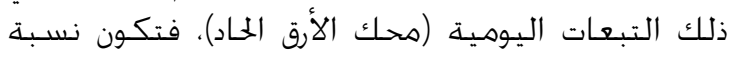

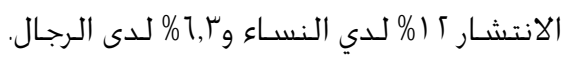

(Li, Wing, Ho, كما فحص كل من لي وونج وهو وفونج \& Fong, 2002)

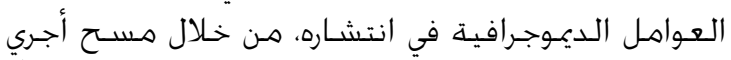

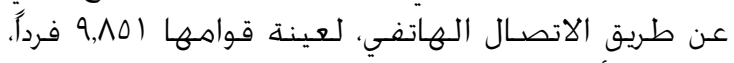

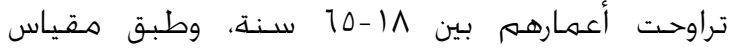

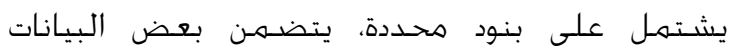
الديموجرافية، وعادات النوم، وأعراض الأرق، ونمط الدهن الحياة.

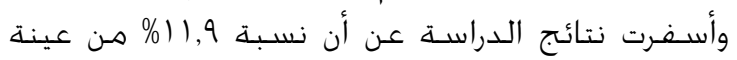

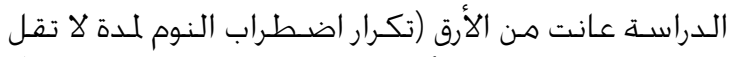

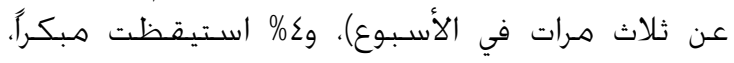

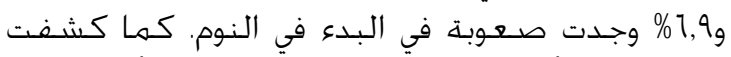

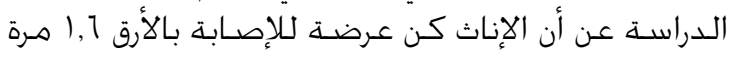

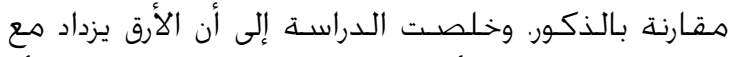

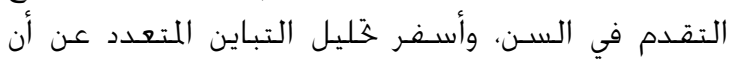

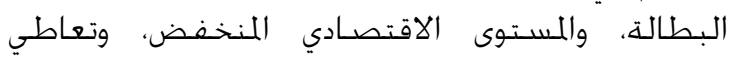

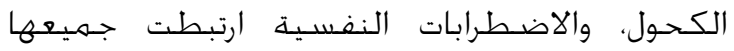

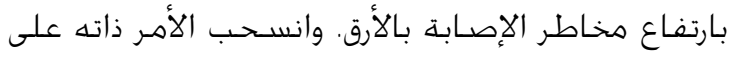

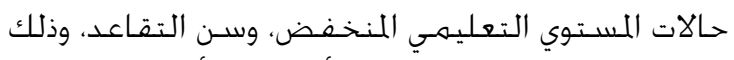

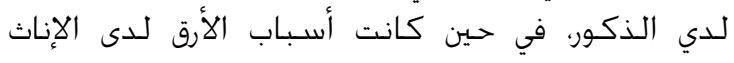

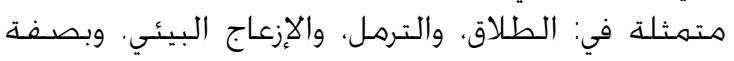

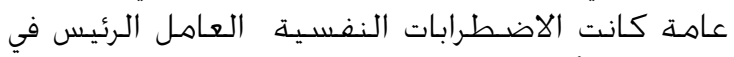
الإصـابة بالأرق لدي الجنسيـين.

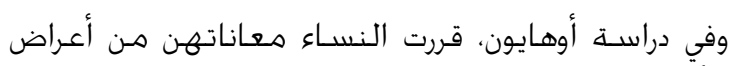

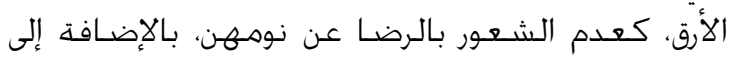

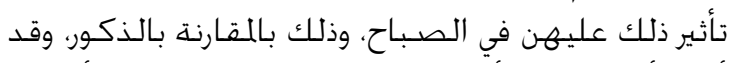

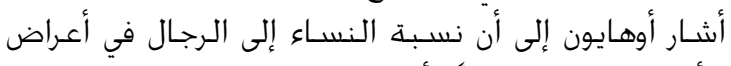

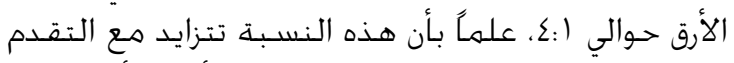

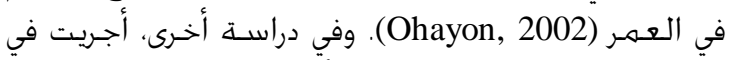

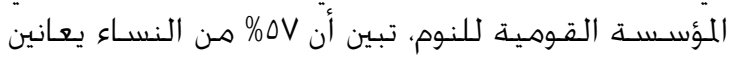
من أعراض الأرق (National Sleep Foundation, 2005). وقام كل من زانج وونج (Zhang \& Wing, 2006) بدراسـة

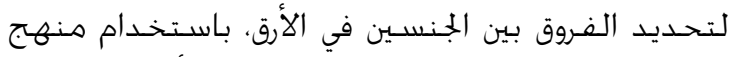

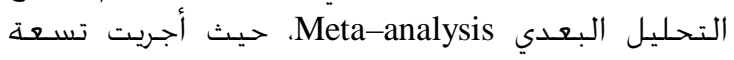

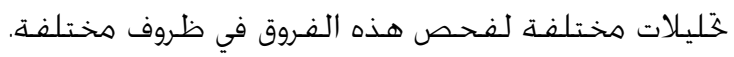

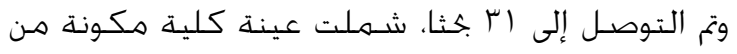


نوعية حياتهم سـلبًا. وتستخدم هذه الدراسـة عينات هن

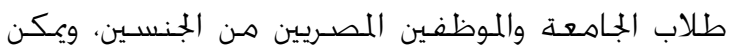
تلخيص مشـكلة الدراسـة في التسـاؤلات الآتية:

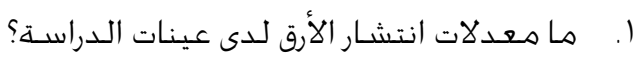
آ. هل هناك فروق جوهرية بين الجنسين في الأرق؟ ماك

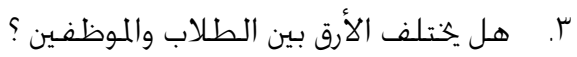

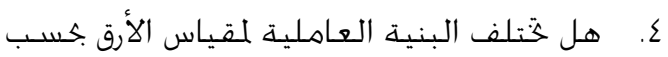
الجنس ، و المرحلة العمرية؟ العاملئ

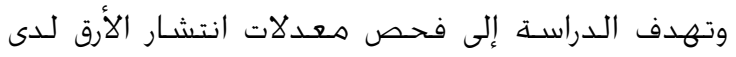

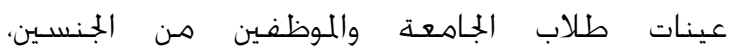

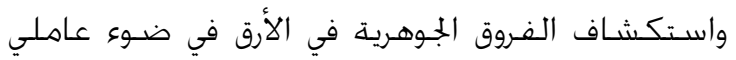

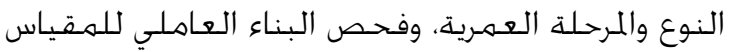
العربي للأرق على عينات الدراسـة.

أهـمية الدراسـة

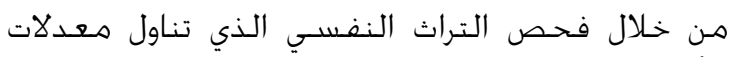
الأرق من حيث معدلات فيت الانتشار والفروق بين الجنسيـين.

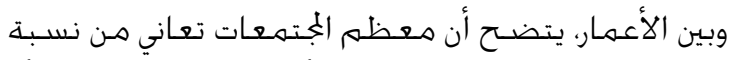

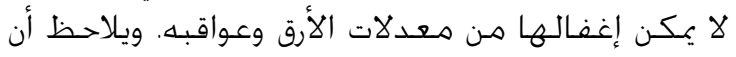

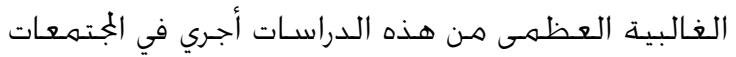

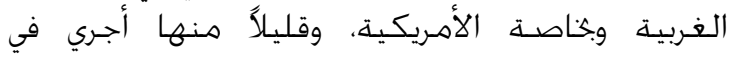

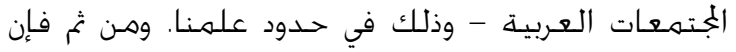

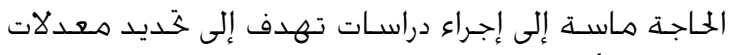

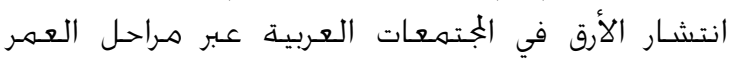

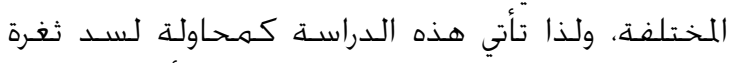

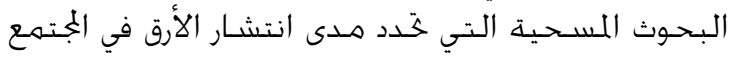

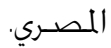

وتتحـدد أهـمية الدراســـ في الفئات التي وقع الاختيار

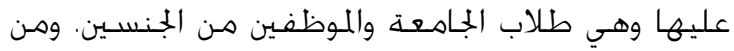

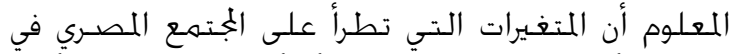

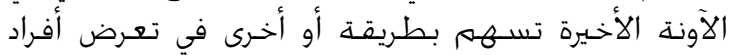

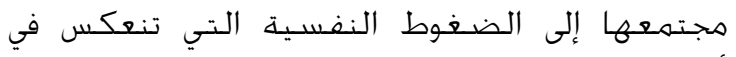

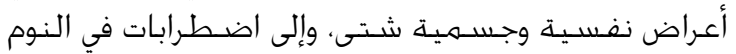

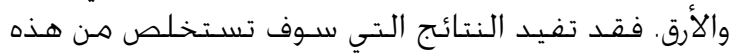

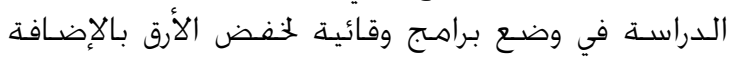

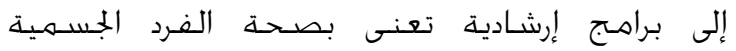

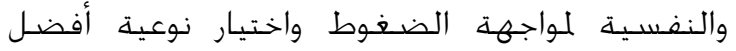
للحياة، لمواجهة الأرق والتغلب عليه.

فروض الدراســ

تســهـدف هذه الدراسـة التحقق مـ الفروض الآتية:

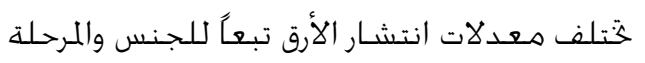
العمـرية.
النوم) والأعراض الجسمية، لدى عينتين هـن المراهقين

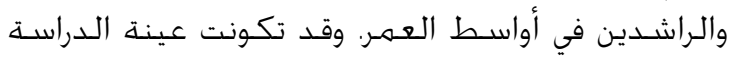

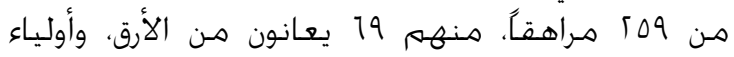

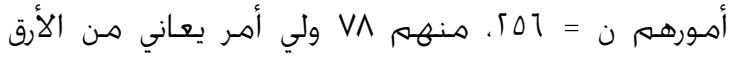

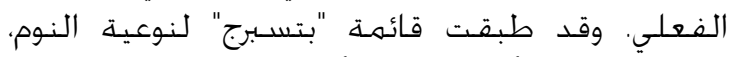

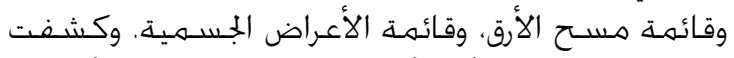

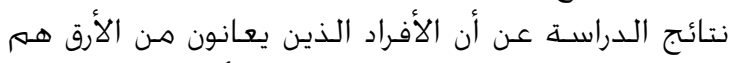

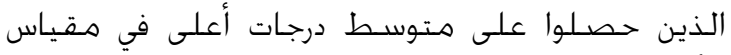

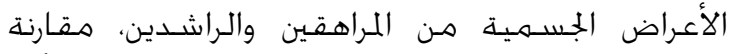

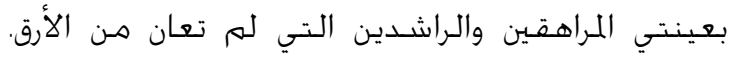

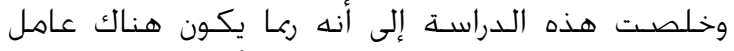

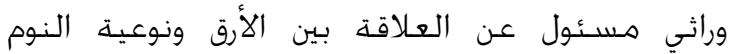
والأعراض الجسـمية.

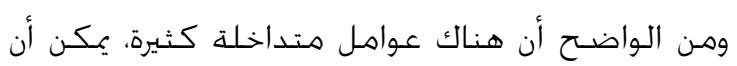

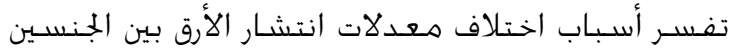

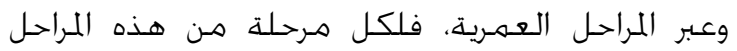

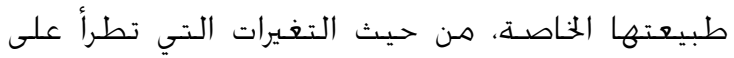

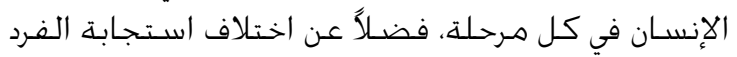

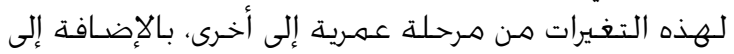

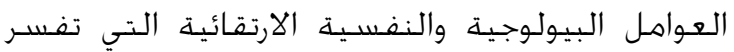

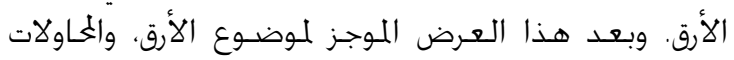

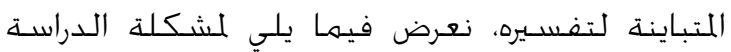
وأهدافها.

\section{مشكلة الدراسـة وأهدافها}

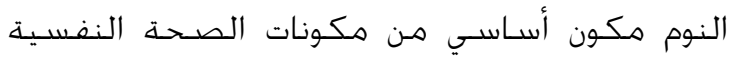

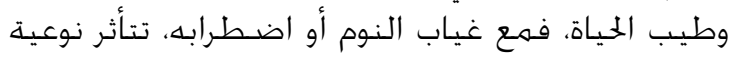

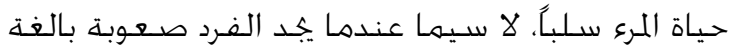

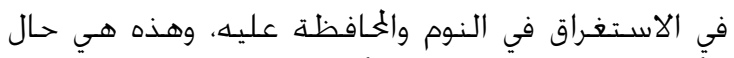

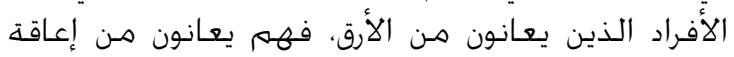

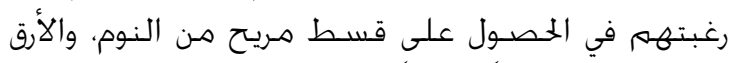

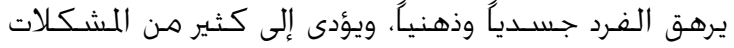

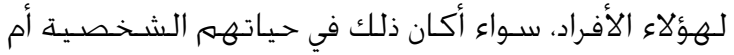

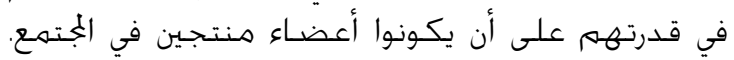

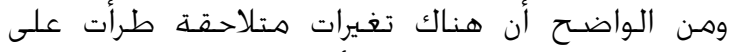

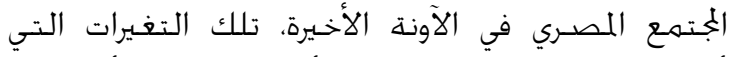

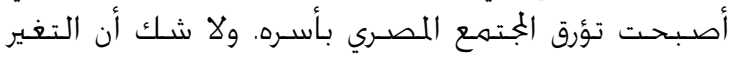

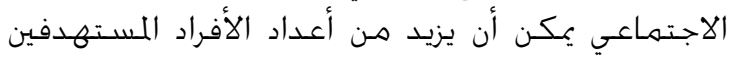

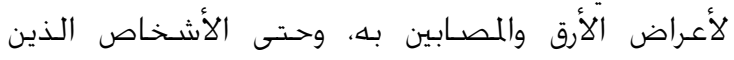

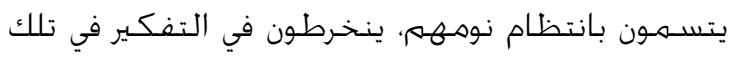

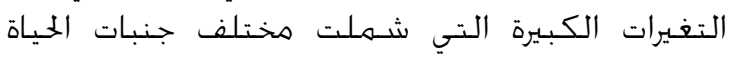

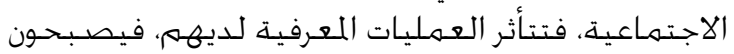

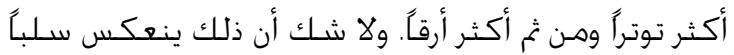
على أدائهمه وعلى علاقاتهم الاجتماعية، وعلى ألى أنماط

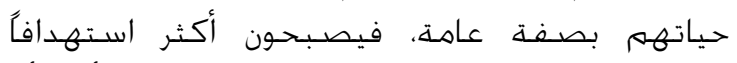
للاضطراب، وختّل صحتهمه النفسية، بل يمكن أن تتأثر 
وتمت مراجعته بدقة. وللمقياس خـواص سيكومترية

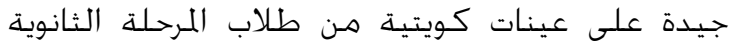
والجامعات والموظفين. وقد تراوحت معاملات معنات ثبات إعادة

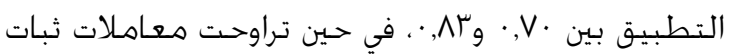

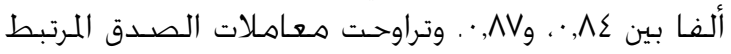

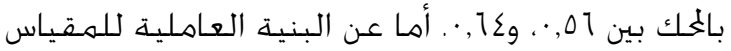

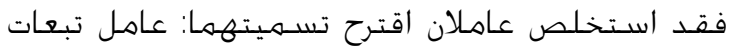

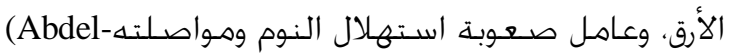
Khalek, 2008)

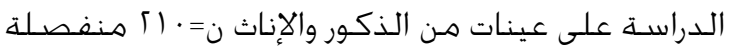

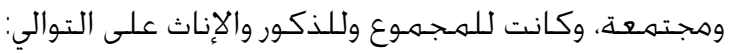

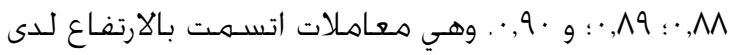

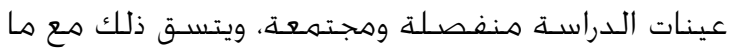

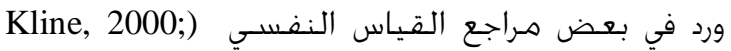
Nunnally, 1978)

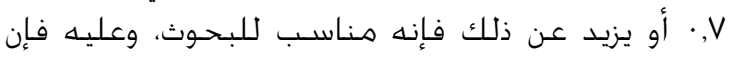

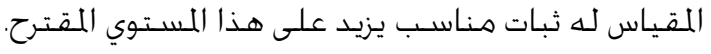

\section{التحليلات الإحصائية}

للتحقق هـ صـحة الفـروض استخـدمت المعالجات الإحصائية الآتية:

ا. النسبة المئوية لإجابات المبحـوثين في البديلين

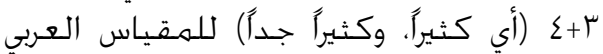

للأرق. ז. المتوسـطات والاخخرافات المعيارية.

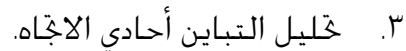

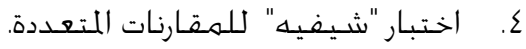
0. التحليل العاملي بطريقـة المكونات الأسـاسـيـة.

\section{نتائج الدراسـة}

ا. اختبار الفـرض الأول، "ختّلف معـدلات انتشـار

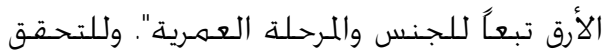

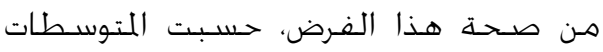

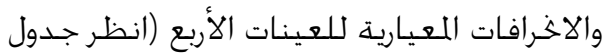

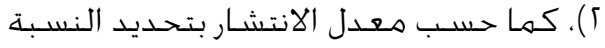

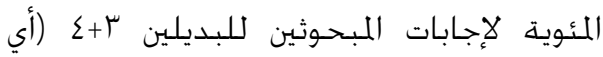

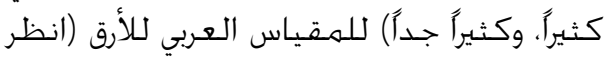

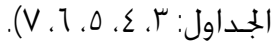

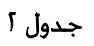
المتوسطات (م) والاخرافات المعيارية (ع) للدرجة الكلية

\begin{tabular}{|c|c|c|c|}
\hline$\varepsilon$ & p & ن ن & الجمهموعة \\
\hline 9,17 & $1\{, \wedge 1$ & 10. & طلبة الجامعة \\
\hline$\wedge, \wedge 9$ & 17,90 & 10. & طالبات الجامعة \\
\hline$\wedge, 17$ & $1 \%, 1 \mathrm{~V}$ & 110 & موظفون \\
\hline $9, \Gamma \mathrm{V}$ & $11, \wedge r$ & ז' & موظفات \\
\hline
\end{tabular}

هناك فروق ذات دلالة إحصـائية في الأرق بحسب الجسب الجنس، والمرحلة العـمرية.

خُتـلف البنية العاملية لبنـود المقياس العربي للأرق باختلاف المرحلة العمـرية.

\section{الطريقـة والإجراءات}

المنهج

اسـتخـدم المنهـج الوصفي المقارن، وذلك لملاءمته لطبيعة هذه الـراســـ وأهـدافهـا.

عينة الدراسـة

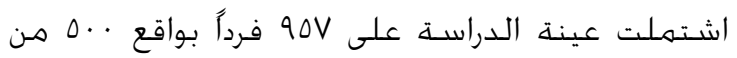

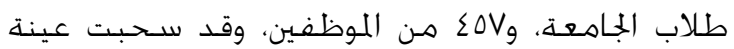

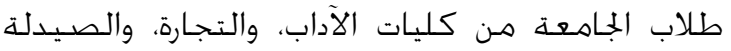

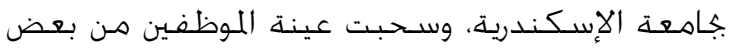

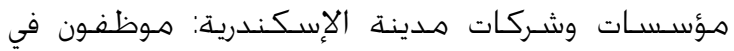

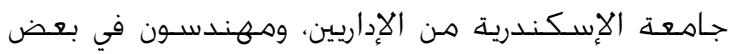

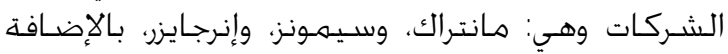

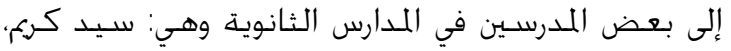

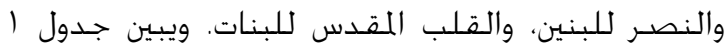

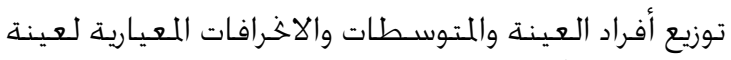

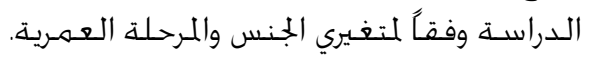

جدول المتوس

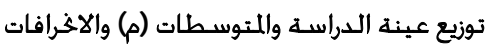

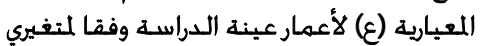

\begin{tabular}{|c|c|c|c|c|c|c|}
\hline \multicolumn{7}{|c|}{ الجنس والمرحلة العمرية } \\
\hline \multicolumn{3}{|c|}{ الموظفون } & \multicolumn{3}{|c|}{ طلاب الجامعة } & \\
\hline$\varepsilon$ & e & ن & $\varepsilon$ & e & ن & \\
\hline$\Lambda, 1$ & $r 1,0$ & 150 & $\Gamma, \cdot$ & $19, \mathrm{~V}$ & ro. & الذكور \\
\hline$\Lambda, r$ & $\mu \mu, 1$ & irt & 1,1 & 19,1 & ro. & الإناث \\
\hline
\end{tabular}

أداة الدراســـ - ماس

The Arabic Scale of Insomnia المقياس العربي للأرق : (ASI)

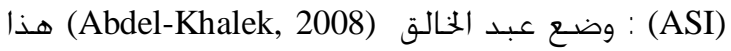

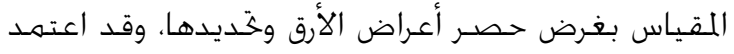

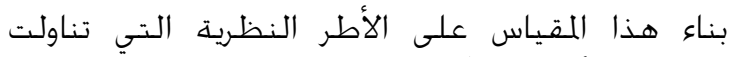

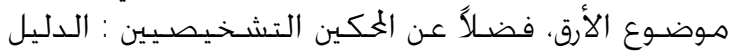

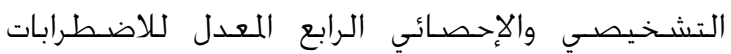

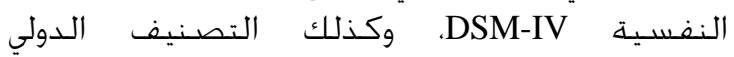

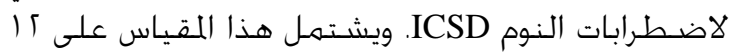

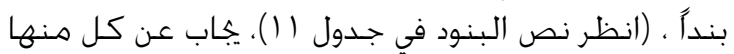

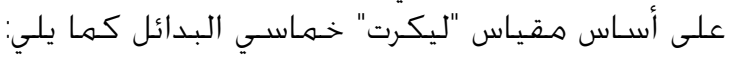

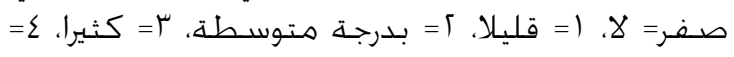

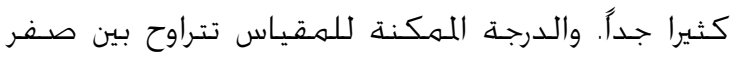

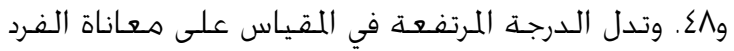

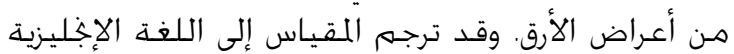


يسبب لي ضيقاً شـيدًا" وذلك لعينة الذكور. كما

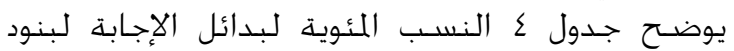
مقياس الأرق لدى عينة طالبات الجامعة.

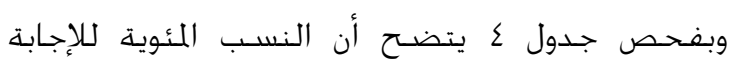

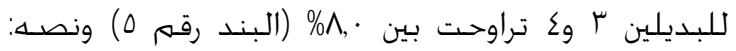

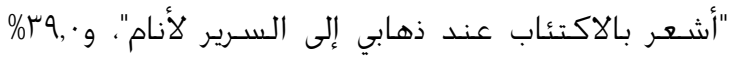

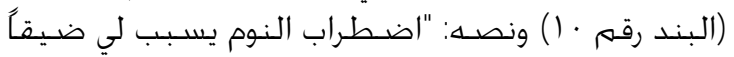
شـيداً" وذلك لعينة الطالبات. ويوضح جدول ه النسب المئوية لبدائل الإجابة لبنود مقياس الأرق لدى عينة الموظفين الذكور والإناث.
يتضح من جدول ؟ أن عينة طالبات الجامعة حصلت

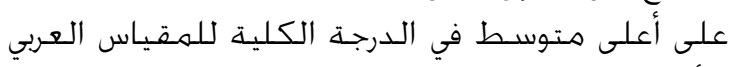

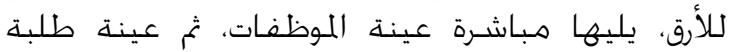

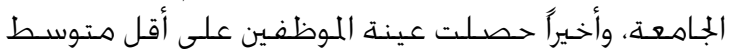

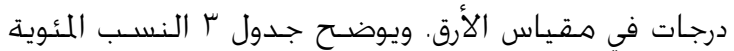

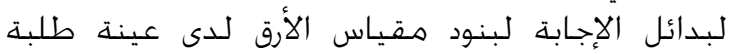

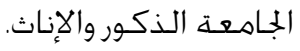

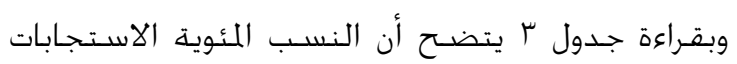

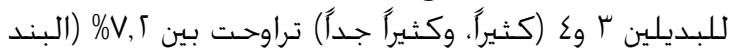

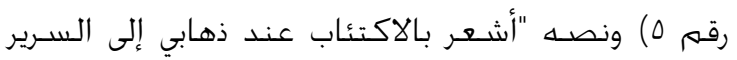

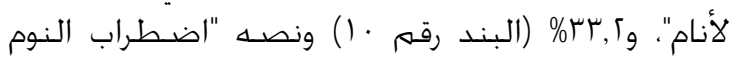

جدول r بلد

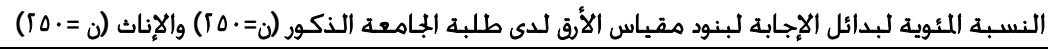

\begin{tabular}{|c|c|c|c|c|c|c|c|c|c|c|c|c|}
\hline & $\varepsilon+\mu$ & & كثيراً & & كثيراً = & & متوس & & قليلا = & & لا = صفر & البند \\
\hline إناث & ذكور & إناث & ذكور & إناث & ذكور & إناث & ذكور & إناث & ذكور & إناث & ذكور & \\
\hline$\Gamma \Lambda, \Sigma$ & 19,5 & $1 \cdot, \cdot$ & 9,1 & $1 \wedge, \Sigma$ & $1 \cdot, \cdot$ & $\Gamma \mathrm{V}, \cdot$ & $\Gamma 1,$. & $\mu \mu$. & $\mu \tau,$. & $1 \Gamma$ & $\tau \mu$. & 1 \\
\hline$\Gamma \varphi$ & $1 \%$. & $\Lambda$ & $0, \cdot$ & $1 \varepsilon$, & $\Lambda$, & 19,7 & IV. & rו, & $r \cdot, \cdot$ & $\Gamma \mathrm{V}, \mathrm{r}$ & ¿1, & r \\
\hline 19. & 11,5 & $1, \cdot$ & $r, \Gamma$ & $1 \%$ & $\Lambda$ & IV, & $1 \varepsilon, \Sigma$ & $\varepsilon \cdot, \cdot$ & $r V, r$ & $\lceil\varepsilon, \varepsilon$ & $r V, r$ & $r$ \\
\hline$\lceil 1, \Sigma$ & $\lceil\varepsilon, \Sigma$ & $1<, \Sigma$ & $19, \Sigma$ & 15, & 11, & $\lceil\varepsilon,$. & $1 \Lambda, \Sigma$ & $\lceil\lceil, \Sigma$ & 11 & $\Gamma \mathrm{V}, \Gamma$ & $\mu \tau,$. & $\varepsilon$ \\
\hline$\Lambda$ & $\mathrm{V}, \Gamma$ & $r,$. & $r, r$ & $\Delta$, & $\varepsilon$, & $\Lambda, \Sigma$ & $\Lambda$ & $1 \varepsilon$, & $11, \Gamma$ & $V \cdot, \Sigma$ & $\mathrm{V} \varepsilon$, & 0 \\
\hline$r \cdot, \cdot$ & $\lceil\mathrm{V}, 1$ & 15, & $1 \Gamma, \Sigma$ & I^. & 10,5 & $1 \varepsilon, \cdot$ & $14, \Gamma$ & $\Gamma 0, \Gamma$ & $\lceil\Lambda, \Sigma$ & r). & r),. & 1 \\
\hline$\Gamma_{1}, \cdot$ & iV, & $\Lambda, \varepsilon$ & $1 \cdot, \Sigma$ & $1 \%, r$ & $11, \Sigma$ & $19,$. & $\lceil 1, \Gamma$ & $19, \Gamma$ & TV & $\lceil\cdot, \Sigma$ & $\Gamma 0, \Gamma$ & V \\
\hline 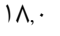 & 15, & $\varepsilon, \cdot$ & $\varepsilon$, & $1 \varepsilon, \cdot$ & $\Lambda$, & 10 & $1 \varepsilon,$. & $\mu \Gamma, \cdot$ & 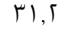 & ro,r & $\sum \mu, \Gamma$ & $\wedge$ \\
\hline $1 \varepsilon$, & 10. & $\Sigma, \Sigma$ & $1, \Sigma$ & $1 \cdot, \cdot$ & $\Lambda, \Sigma$ & 17, & $1 \cdot, \cdot$ & IT, & $\Gamma \mu$ & $\Sigma \Lambda, \Sigma$ & $\Delta \Gamma, \Sigma$ & 9 \\
\hline rq. & $\mu \mu, \Gamma$ & $\lceil\cdot, \cdot$ & 15, & $19, \Gamma$ & $\lceil 1, \Gamma$ & $\lceil\cdot, \Sigma$ & I^. & $\lceil\cdot, \cdot$ & $\lceil\lceil, \Sigma$ & {$[1, \cdot$} & $\Gamma \mathrm{V}$, & 1. \\
\hline$\lceil\cdot, \cdot$ & IV, & $\mathrm{V}, \Gamma$ & $1, \cdot$ & $1 \Gamma, \Sigma$ & $11, \Gamma$ & $1 \varepsilon, \varepsilon$ & 15 & $\lceil\cdot, \cdot$ & $\lceil\zeta, \Sigma$ & $\Sigma 1, \Sigma$ & $\sum V, \Gamma$ & 11 \\
\hline$\lceil\wedge, \Sigma$ & $\Gamma q$. & $1 \varepsilon$, & 11, & $\mid \varepsilon, \Sigma$ & $\mid \wedge$ & $\lceil\Gamma, \Sigma$ & $1 \varepsilon_{,}$ & $\lceil\varepsilon$, & $\Gamma \mathrm{V}, \Gamma$ & ז1,. & $r \cdot, \cdot$ & 11 \\
\hline
\end{tabular}

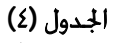

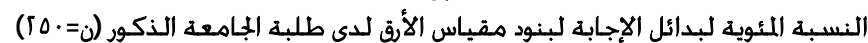

\begin{tabular}{|c|c|c|c|c|c|c|}
\hline$\varepsilon+r$ & كثيراً جداً & كثيراً & متوسط & قليلا & $\begin{array}{c}\gamma \\
\text { صف }\end{array}$ & رقه \\
\hline 19.1 & 9.1 & $1 \cdots$ & T1. & r.. & $\Gamma \mu$. & 1 \\
\hline 14. & 0, & $\Lambda$. & IV. & $r \cdot$. & $\sum 1$. & 广 \\
\hline 11.5 & r.r & $\Lambda$. & $1 \varepsilon . \varepsilon$ & FV.S & FV.T & $r$ \\
\hline 「દ.દ & 15.2 & 15. & $1 \Lambda . \varepsilon$ & $\lceil 7$ & Mr. & $\varepsilon$ \\
\hline
\end{tabular}

جدول 0 الارق 0

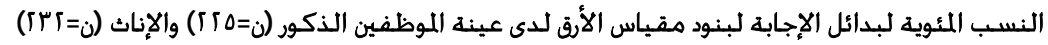

\begin{tabular}{|c|c|c|c|c|c|c|c|c|c|c|c|c|}
\hline \multicolumn{2}{|c|}{$\varepsilon+r$} & \multicolumn{2}{|c|}{ كثيرً جـاً= } & \multicolumn{2}{|c|}{ كثيرً= } & \multicolumn{2}{|c|}{ متوسـط = } & \multicolumn{2}{|c|}{ قليلا= 1} & \multicolumn{2}{|c|}{ لا = صفر } & \multirow[t]{2}{*}{ رقبند } \\
\hline إناث & ذكور & إناث & ذكور & إناث & ذكور & إناث & ذكور & إناث & ذكور & إناث & ذكور & \\
\hline$\Gamma \Gamma, \Sigma$ & 11 & $1, \Sigma$ & $\mathrm{V}, 1$ & 17 & 9, & $\Gamma \Gamma$, & 11,2 & TV, & $r \cdot, r$ & $\Gamma 9$, & $r V, r$ & 1 \\
\hline$\Gamma \varepsilon, 0$ & 15, & 9, & $r, 0$ & 17. & $\Lambda, \Sigma$ & $\lceil\varepsilon, 1$ & $1 \Lambda, \Gamma$ & $\Gamma 0, \Sigma$ & $r^{\mu, 0}$ & $\lceil 1$, & $\sum 1, \Gamma$ & $\Gamma$ \\
\hline iv, & $1 \%, r$ & $9, \Sigma$ & $\varepsilon_{,} \cdot$ & IV,r & $9, r$ & $19, \varepsilon$ & $\lceil\Gamma, 1$ & $r \mu, 1$ & $\mu 1,$. & {$[1$,} & $\mu r, \mu$ & $r$ \\
\hline$\varepsilon r$. & $\Gamma 0, r$ & IV,r & $9, r$ & $\Gamma 0, \varepsilon$ & 11 & $1 \%$. & iv, & $\Gamma 0$, & $\Gamma r, 1$ & 19,2 & $\lceil 9$, & $\varepsilon$ \\
\hline$\Lambda, 1$ & $0, r$ & $\cdot, \wedge$ & $\cdot, 9$ & $V, r$ & $\varepsilon, \Sigma$ & 9, & $\varepsilon, \cdot$ & $1 \%, r$ & 11,1 & 79,2 & $\Lambda \cdot, \cdot$ & 0 \\
\hline 11. & 10 & $1 \cdot, r$ & $\Sigma, \Sigma$ & $1 \cdot, r$ & $1 \cdot, r$ & $1 \%$. & 10,1 & $r \cdot, l$ & $\lceil 1$, & $r 1, r$ & $\varepsilon \varepsilon, \Sigma$ & 1 \\
\hline$r r,$. & $\lceil\Gamma, \Gamma$ & I $\varepsilon_{\text {. }}$ & $\Lambda, \Sigma$ & $1 \wedge, 1$ & $1 \varepsilon$, & $\lceil 1,0$ & 19,0 & $\lceil\varepsilon, 1$ & $\Gamma \mathrm{V}, \mathrm{O}$ & $\Gamma \Gamma, \Sigma$ & r.,. & v \\
\hline 10 & $9, r$ & $\wedge, 1$ & $\Sigma, \cdot$ & $1, \Sigma$ & $\Delta, r$ & $1 \wedge, 1$ & 11,1 & $\Gamma 0, \Sigma$ & $\lceil\mathrm{V}, 1$ & $\sum \Gamma$, & $\Delta \Gamma, \Sigma$ & $\wedge$ \\
\hline IV, & 11,0 & $V, r$ & $\lceil, 1$ & 9,2 & 9, & 11,1 & 11,0 & $\Gamma \mu$. & $i t, \Gamma$ & $\Sigma 9$, & $\Delta \Delta$ & 9 \\
\hline$\sum \mu, 1$ & $r \varepsilon, \Gamma$ & 19,2 & 11,1 & $\Gamma \varepsilon$, & $\lceil r, 1$ & $19, \varepsilon$ & $\Gamma \cdot, \cdot$ & 19. & זT, & $1 \wedge, 0$ & $\lceil\varepsilon$, & 1. \\
\hline$\Gamma \cdot, \Gamma$ & 19,0 & 0,1 & $0, r$ & 10 & $1 \varepsilon, \Gamma$ & $11, r$ & $1 \Lambda$ & $\lceil\Gamma, \Sigma$ & $\lceil 1, \cdot$ & $\sum 1$, & $r v$, & 11 \\
\hline 10, & 19,1 & 0,1 & $\Lambda$ & $9, \Sigma$ & 11,1 & 17, & $1 \Lambda, \Gamma$ & $\mu 1, \Gamma$ & iv, & $\mu \mu, 1$ & $\mu_{1},$. & 15 \\
\hline
\end{tabular}




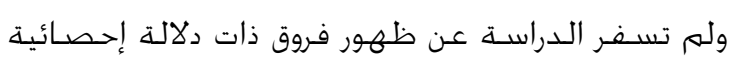

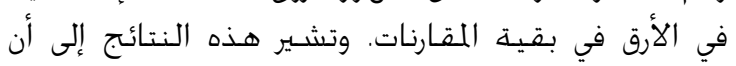

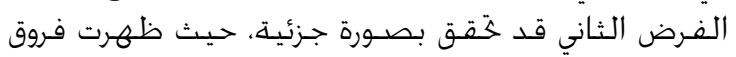

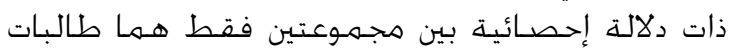
الجامعة والموظفين، والموظفين والموظفات.

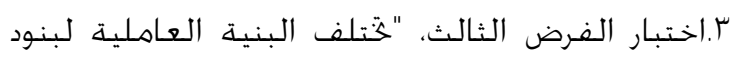

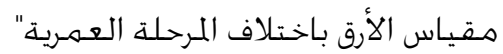

للتحقق من هذا الفرض، استخدم التحليل العاملي

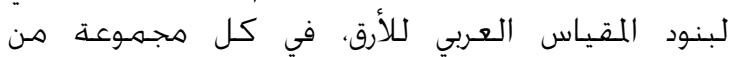

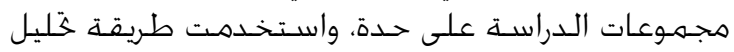
Principle Components Analysis المكونات الأسياسية الدراسية لتحليل معاملات الارتباط بين بنود المقياس في كل عينة

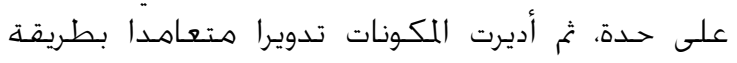

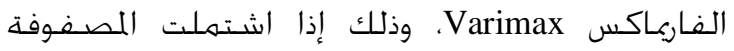

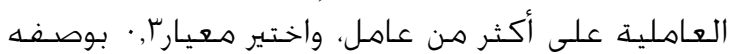

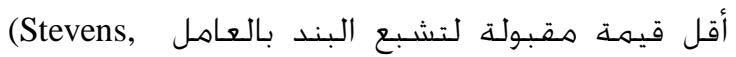

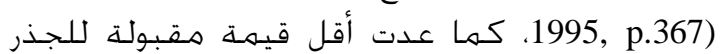

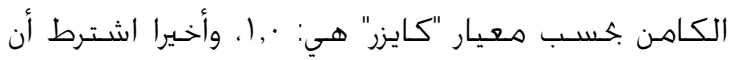

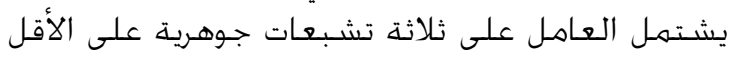
(Stevens, 1995, p.367)

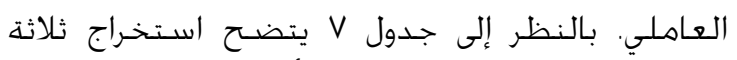

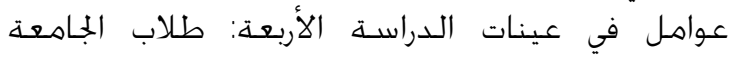

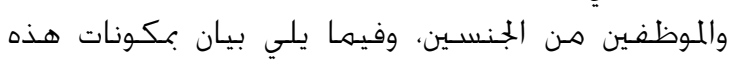

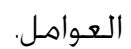

وبالنظر إلى جدول ه يتضح أن النسب المئوية لإجابة

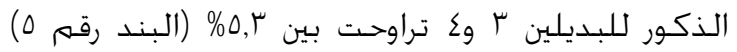

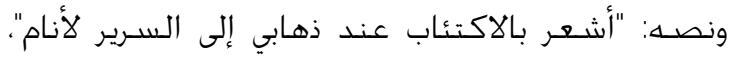

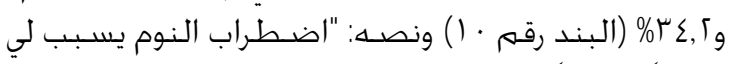
ضيقةًا شـديدًا". (الند

وبفحص جدول ه أيضًاً يتضح أن النسب المئوية

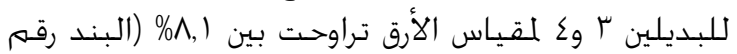

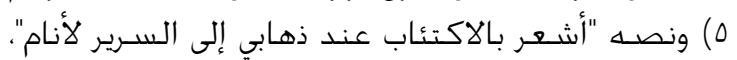

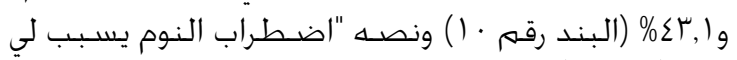

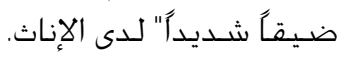

I - اختبار الفرض الثاني، "هناك فروق ذات دلالة إحصائية

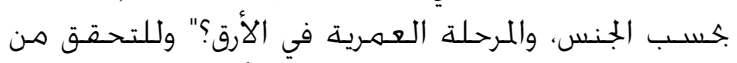

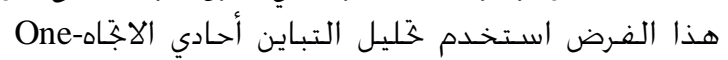

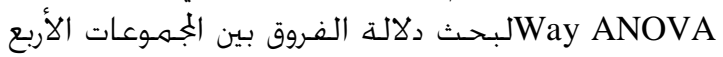

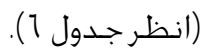

يتضح من جدول 1 وجود فروق دالة إحصائيا بين

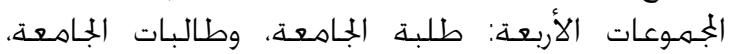

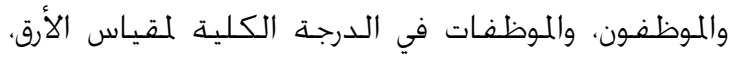

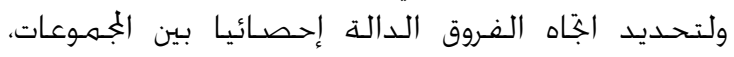

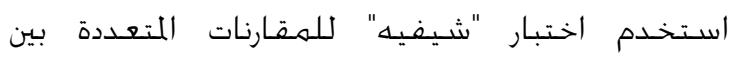

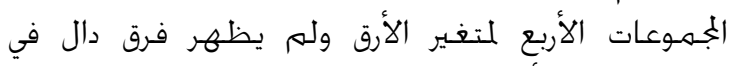

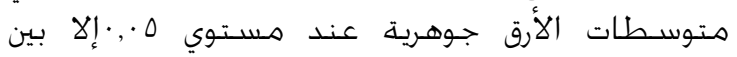

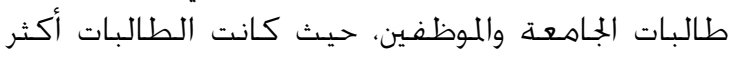

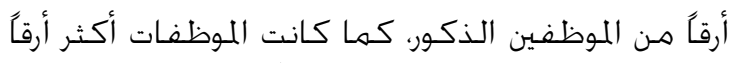

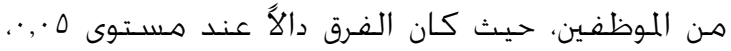

جدول 1

ثلليل التباين أحادي الاجّاه للفروق في الدرجه الكلية لمقياس الأرق تبعا للجنس والجمهوعة

العمرية الدانة

\begin{tabular}{|c|c|c|c|c|c|c|}
\hline \\
\hline الدلالة - م الد & قيمة ف & المربعات & متوسـط & ביז. & مجـموع المربعات & مصـدر التباين \\
\hline & & & $\Delta 9 \mu, \Delta \mu \wedge$ & $r$ & $I \vee \wedge \cdot, 110$ & بين الجُمـوعات \\
\hline$\cdot, \cdots 1$ & $V, \cdot r$ & & $\wedge \varepsilon, r \Delta r$ & 904 & $\Lambda \cdot r \Lambda \Lambda, \Gamma q$. & داخل الجُمـوعات \\
\hline & & & & 901 & $\wedge \Gamma \backslash \backslash \wedge, 9 \cdot \Delta$ & الجمهوع \\
\hline
\end{tabular}

تشبعات العوامل المتعامدة لبنود المقباس العربي للأرق بكسب المرحلة العمرية والجنس

\begin{tabular}{|c|c|c|c|c|c|c|c|c|c|c|c|c|}
\hline \multicolumn{6}{|c|}{ الموظفون } & \multicolumn{6}{|c|}{ طلاب الجامعة } & \multirow{3}{*}{ بنود مقياس الأرق } \\
\hline \multicolumn{3}{|c|}{ إناث ن= Tr } & \multicolumn{3}{|c|}{ ذكور ن=0 } & \multicolumn{2}{|c|}{ إناث ن= = } & \multicolumn{4}{|c|}{ ذكور ن= 10} & \\
\hline عامل؟ & عامل T & عامل 1 & عامل؟ & عامل & عامل & عاملץ" & عامل T & عامل 1 & عاملr & عامل؟ & عامل ا & \\
\hline & $\cdot, \mathrm{V})$. & $\cdot, \mu \uparrow$. & & & $\cdot, \wedge \cdot 1$ & & & $\cdot, 10 \mu$ & & $\cdot, 071$ & $\cdot, \Sigma \cdot V$ & ال أنوم. أجد صعوبة في أن أبدأ \\
\hline & ., 419 & $\cdot, \wedge)$ & & $\cdot, \mu \cdot \Delta$ & $\cdot, \vee \wedge \varepsilon$ & & & $\cdot, \wedge \Sigma \Gamma$ & & $\cdot, \wedge \Sigma 9$ & & مض - نوهي متقطع و \\
\hline & & $\cdot, \wedge \cdot 1$ & & & $\cdot, 7 \wedge 9$ & & & $\cdot, \mathrm{Vq}$. & & $\cdot, \wedge \Sigma 1$ & & r ـ أســيقظ مـن النوم عدة \\
\hline
\end{tabular}




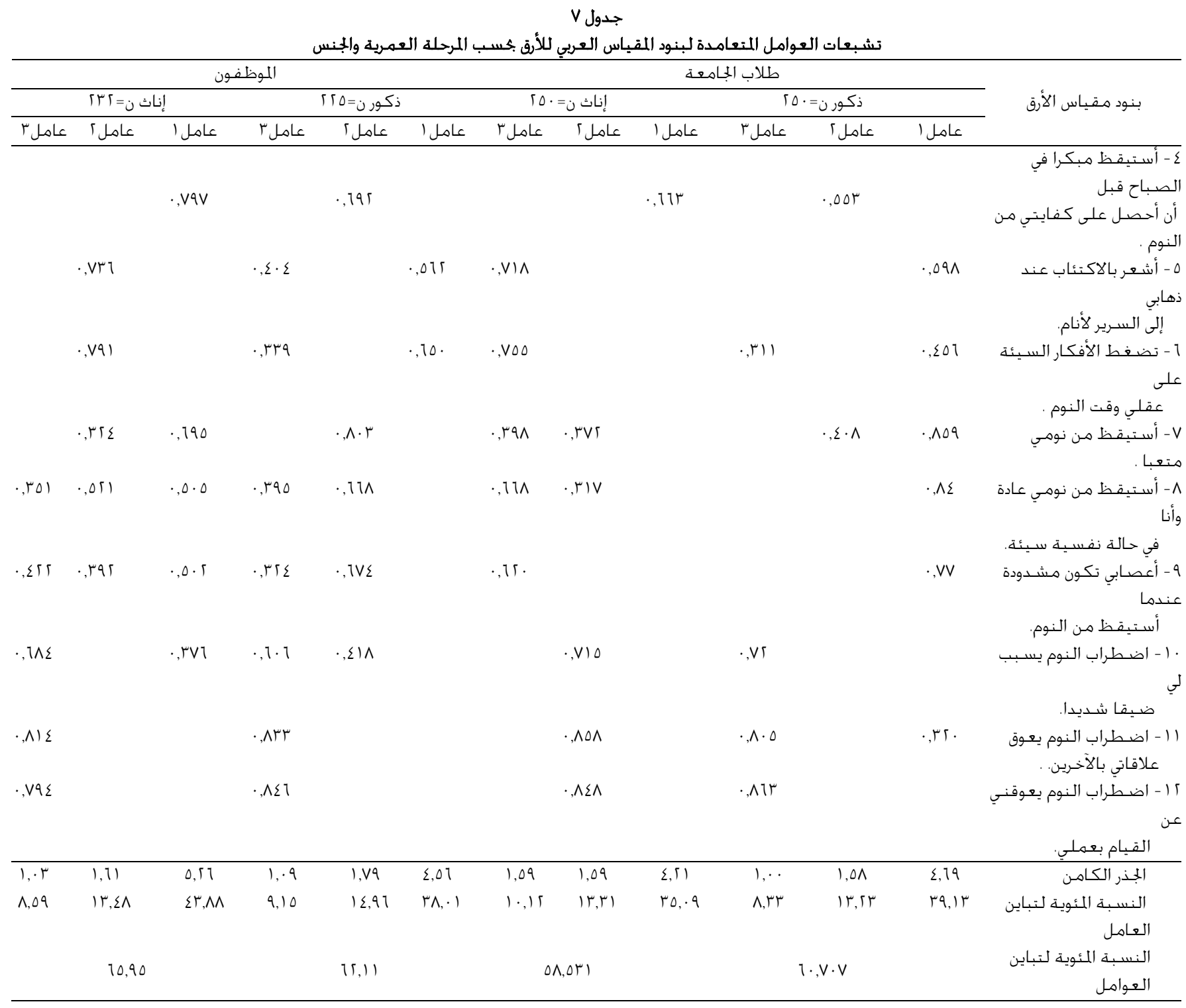

المشبعة بهـا العامل حول الآثار السـلبية للأرق، ويمكن تسـمية هذا العامل: "عواقب الأرق".

ثانيًا: العوامل المستخرجة من عينة طالبات الجامعة:

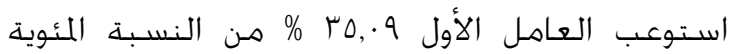

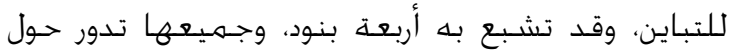

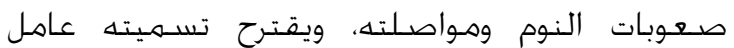

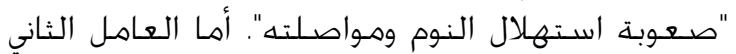

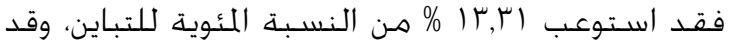

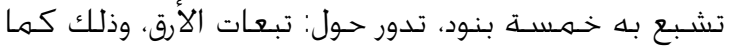

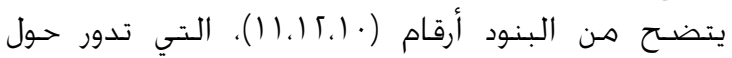

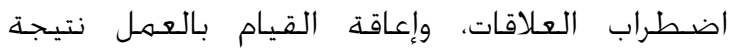

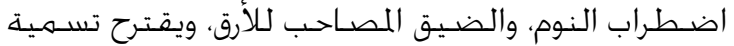

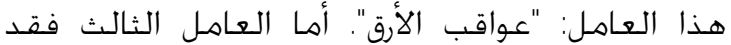

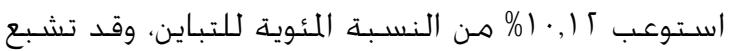

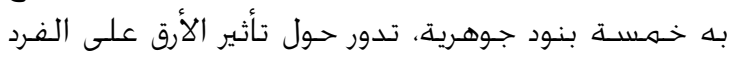

أولً: العواهل المستخرجة من عينة طلبة الجامعة:

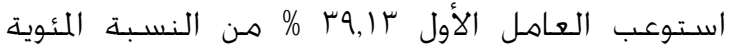

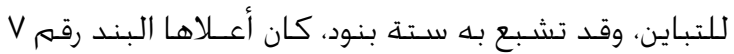

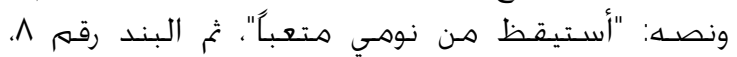

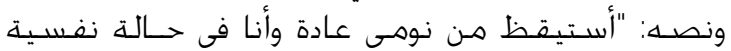

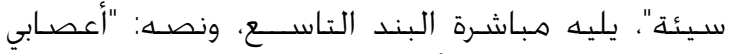

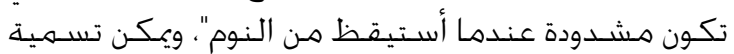

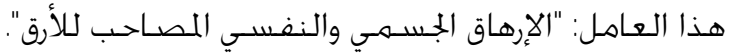

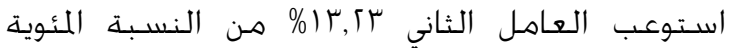

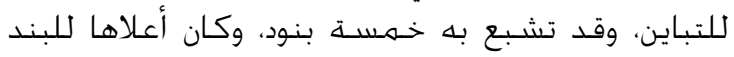

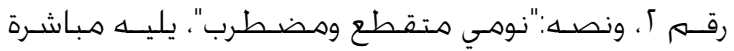

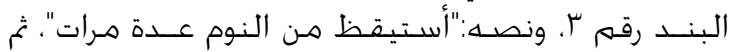
البند رقم ا، ونصـه: "أجد صعوبة في أن أبدأ النوم".

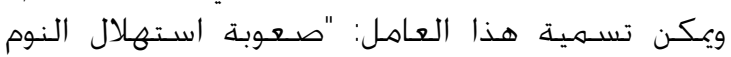

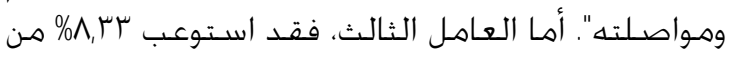

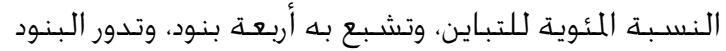




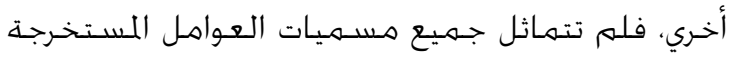

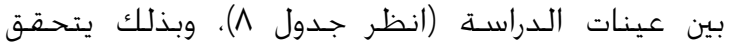
الفرض الثالث من فروض الدراسـة بشكل كلي.

\section{مناقشـة النتائج}

تراوحت معدلات انتشـار الأرق لدى عينة الدراسـة الكلية

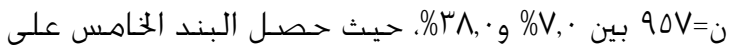

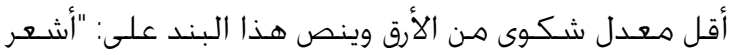

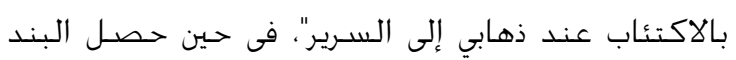

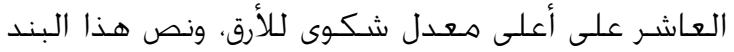

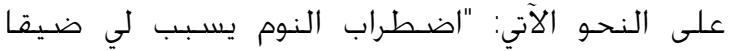

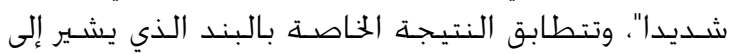

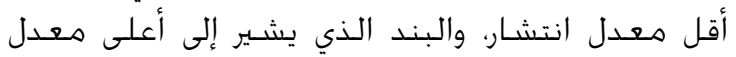

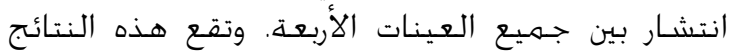

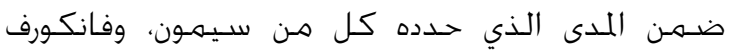
Aimon \& Vankorff

.(Abdel-Khalek, 2004

يتضح مما سبق حصول البند رقم ه الذي ينص على:

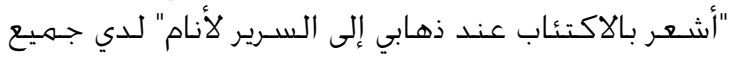

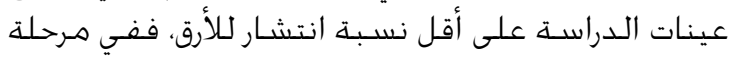

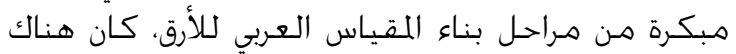

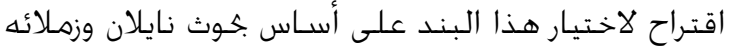
Neylan et al.,

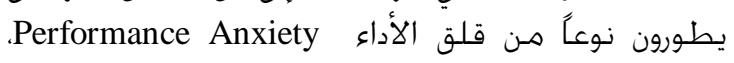

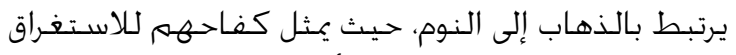

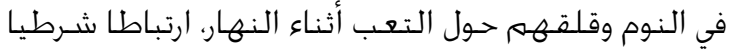
بين سلوك وقت الولوج إلى السـرير واستثارة القلق.

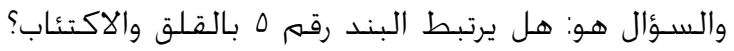

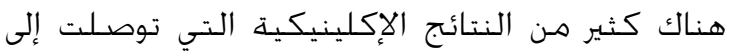

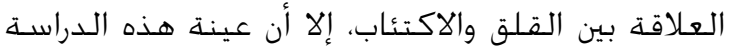

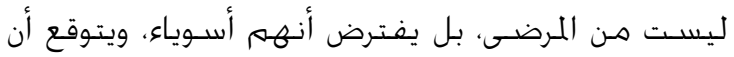

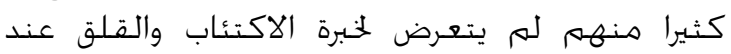

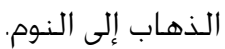

جسـياً ونفسياً. ويقترح تسمية هذا العامل: "الإرهاق

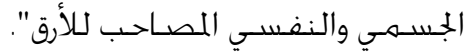

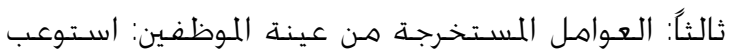

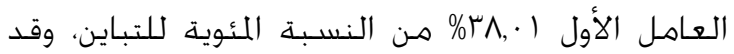

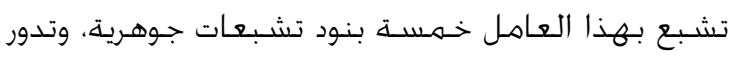

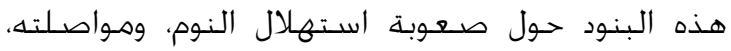

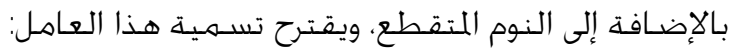

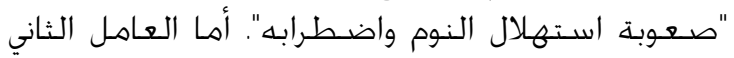

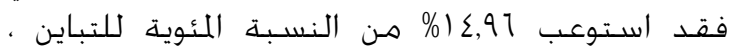

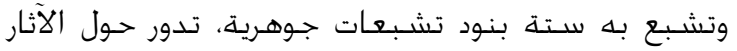
السـلبية للأرق على الفرد سـواء أكان جسـهـانيًا أم نفسيًاً.

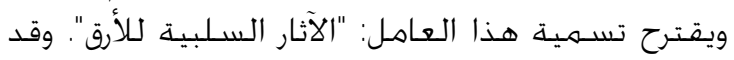

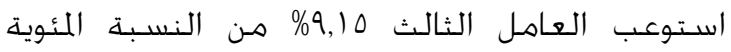

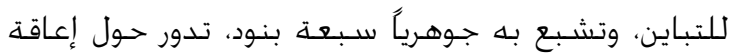

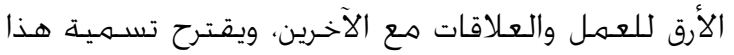

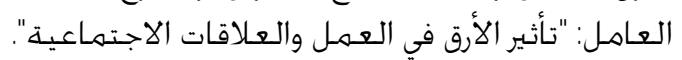

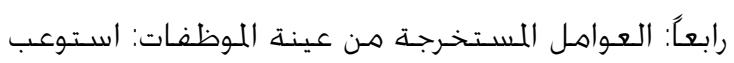

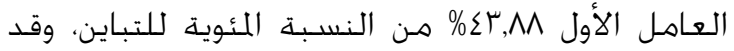

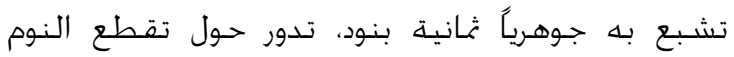

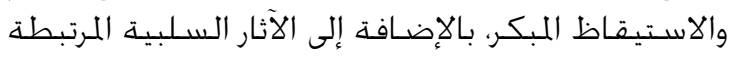

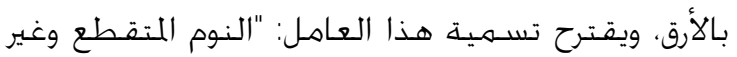

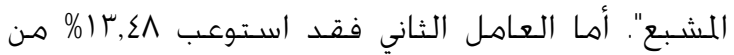

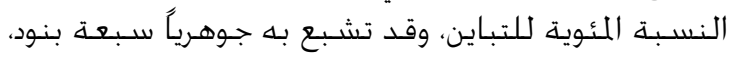

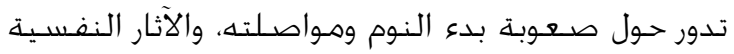

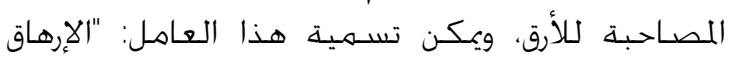

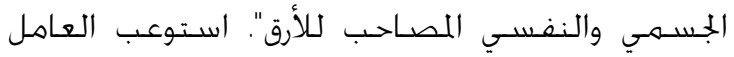

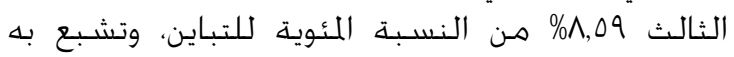

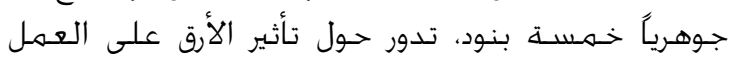

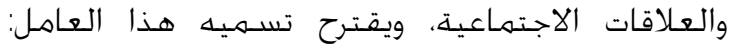

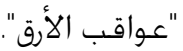
ويوضح جدول ^ مسـميات العوامل المستخرجة من العن العينات الأربعة.

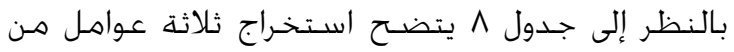
المقياس العربي للأرق لدى العينات الأربعة. ومن ناحية العاهية

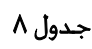

مسميات العوامل المستخرجة من المقياس العربي للأرق لدى الججموعات الأربعة

\begin{tabular}{|c|c|c|c|c|c|}
\hline \multicolumn{5}{|c|}{ عينة طالبات الجامعة } & \multirow{2}{*}{ عينة طلبة الجامعة } \\
\hline عامل r & عامل & عامل 1 & عامل & عامل & \\
\hline الإرهاق الجســـي & عواقب الأرق & صـعوبة اســـلال & عواقب الأرق & صـعوبة استهـلال & الإرهاق الجســي \\
\hline والنفسي المصاحب & & النوم ومواصـلتهـ & & النوم ومواصـلته & والنفسي اللصاحب \\
\hline لـأَرق & & & & & للألأرق \\
\hline \multicolumn{5}{|c|}{ عينة الموظفات } & عينة الموظفين \\
\hline عامل r & عامل r & عامل 1 & عامل r & عامل ؟ & عامل 1 \\
\hline \multirow[t]{3}{*}{ عواقب الأرق } & الإرهاق الجســـي & النوم المتقطع وغير & تأثير الأرق في & الآثار السـلبية للأرق & صعـوبة استهلال \\
\hline & والنفسي & المشبع & العـمل والعـلاقات & & النوم واضـطرابه \\
\hline & اللصاحب للألأرق & & الاجتـماعية & & \\
\hline
\end{tabular}


(Abdel-Khalek \& Alansari, 2004)

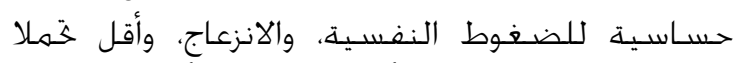
للظروف الضـاغطة، وهي أسـباب كفيلة بأن جَعل الإناث

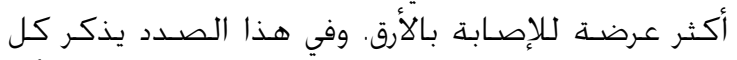

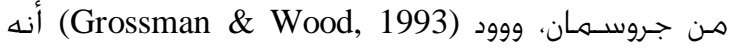

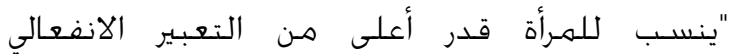

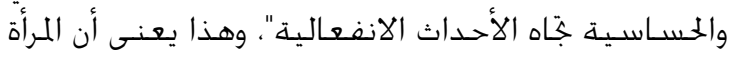

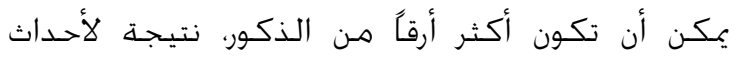

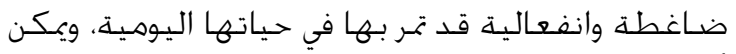
أن تستجيب لتلك الضغوط بشـدة انفعالية عالية، تؤثر

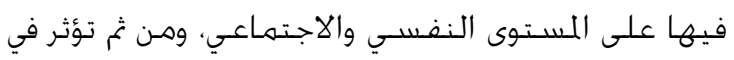
استقرار نومها.

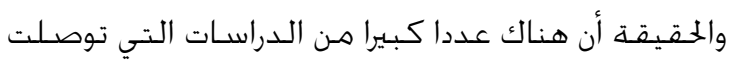

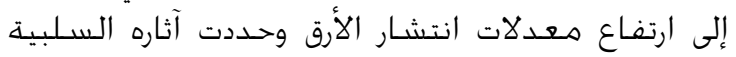

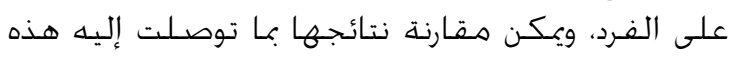

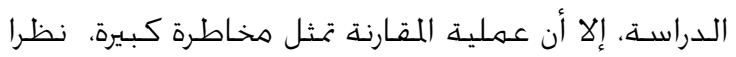

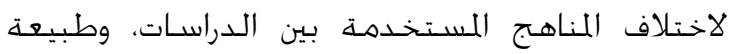
العينات، وطرق اختيارها، بالإضـافة إلى التباين في تعريف اللافيف

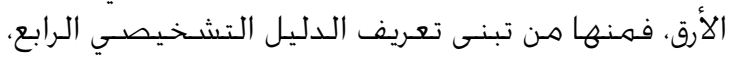

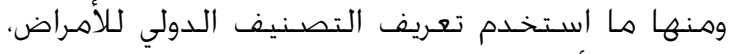

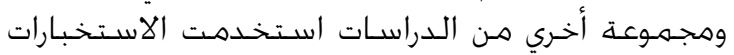

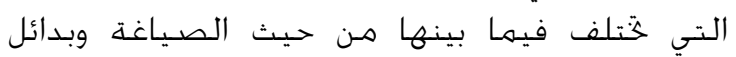
الإجابة (Abdel-Khalek, 2004).

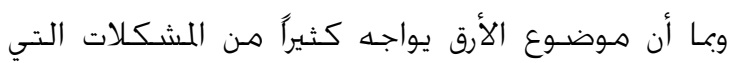

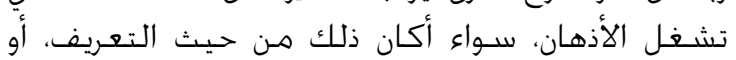

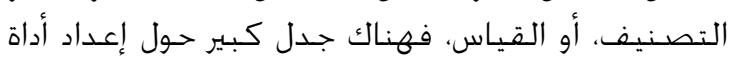

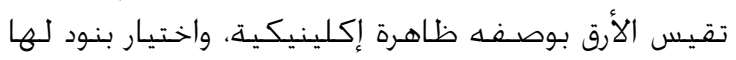

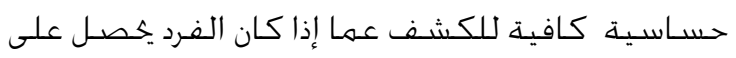

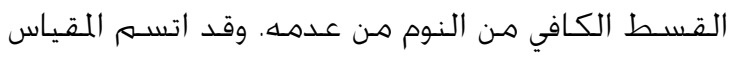

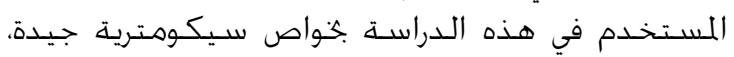

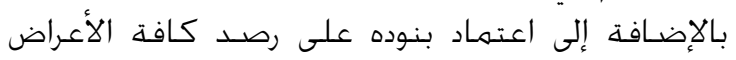

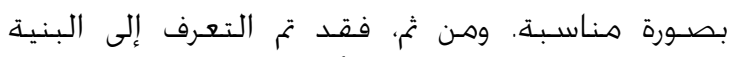

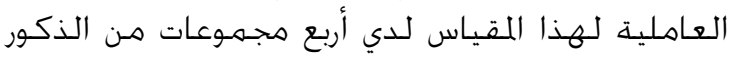

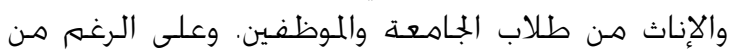

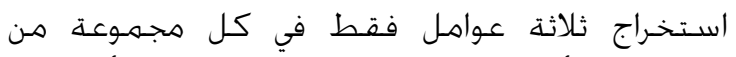
الجمهوعات الأربعة، فلم يكن هنات هناك اتسـاق بين أسـمائها

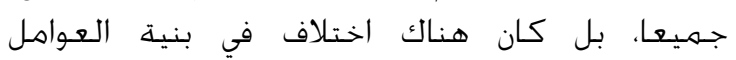

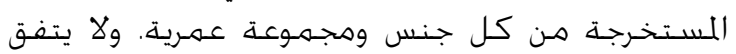

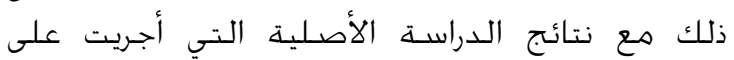

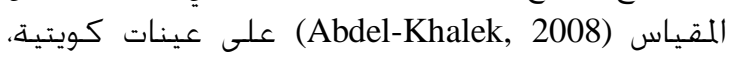

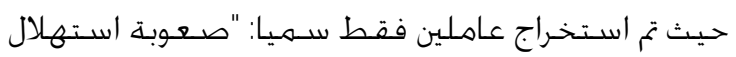

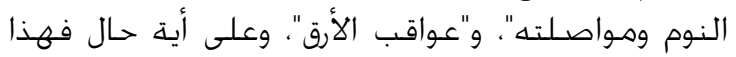

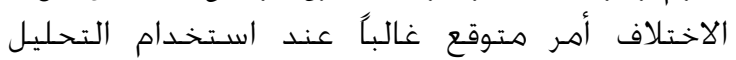

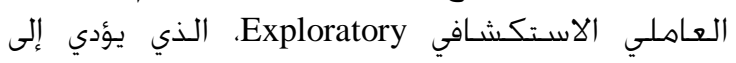

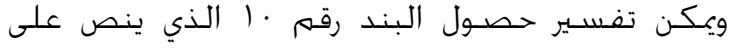

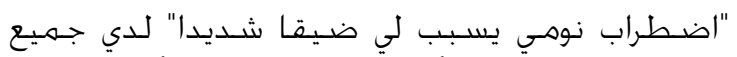

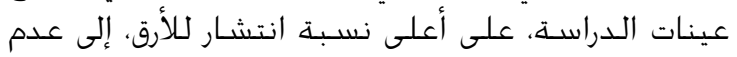

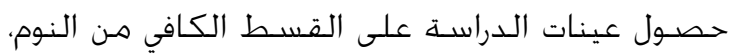

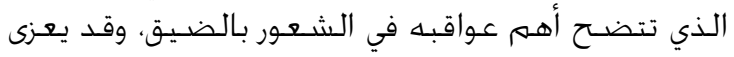

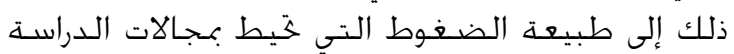

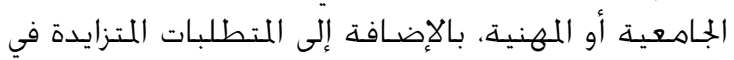

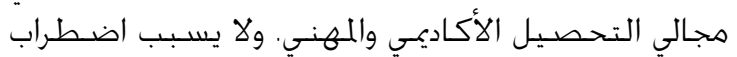

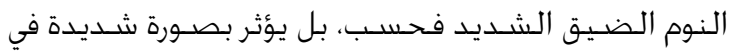

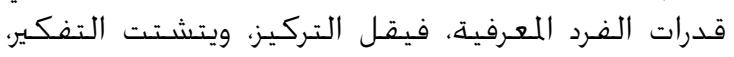
وينخفض الأدراء.

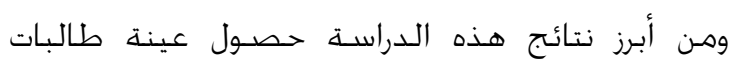
الجامعة على أعلى متوسط هذه درجات في في مقياس الأرقات

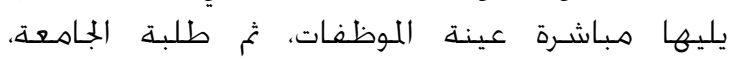

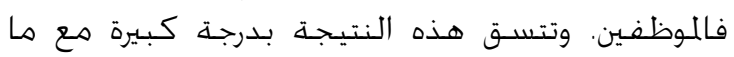

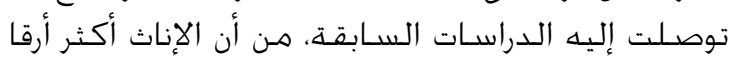

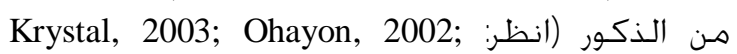

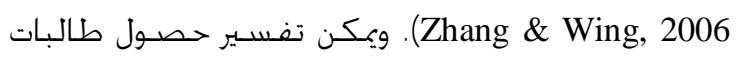

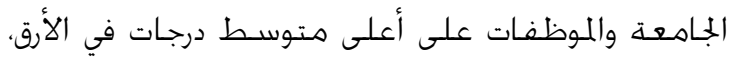

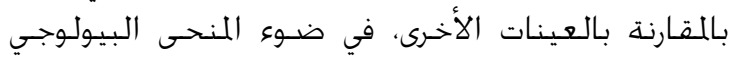

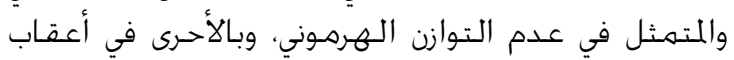

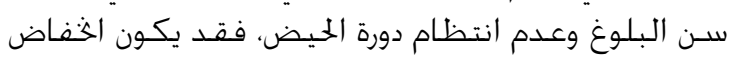

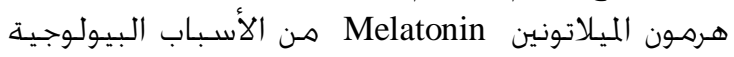

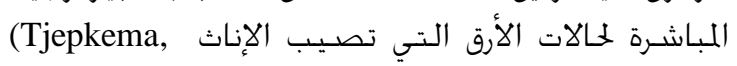

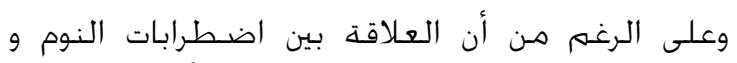

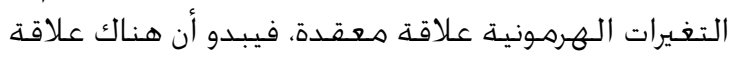

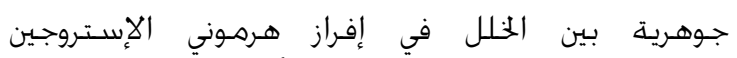

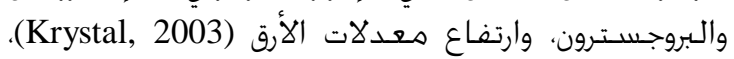

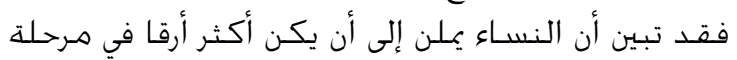

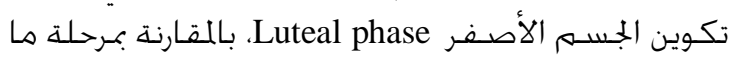

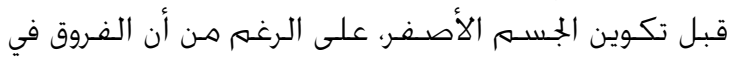

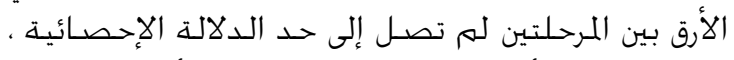

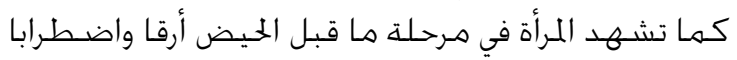

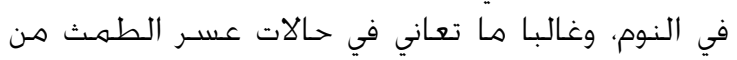

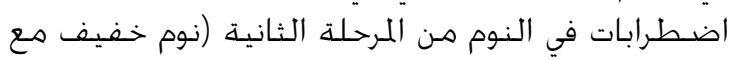
انتفاء حركات العين) (Hudson, 2004).

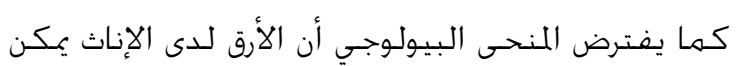

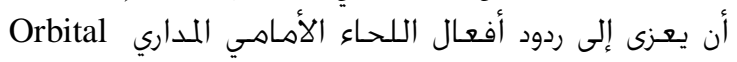

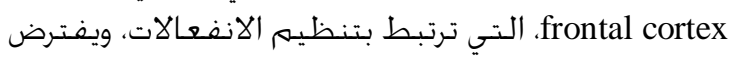

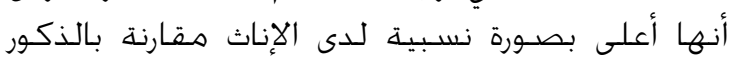
(Gur, Gunning-Dixon, Bilker, \& Gur, 2002)

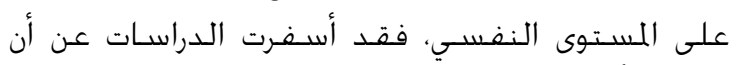

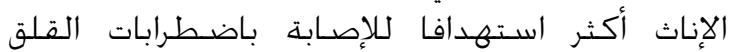


A bdel-Khalek, A. M. (2004). Prevalence of reported insomnia and its consequences in a survey of 5,044 adolescents in Kuwait. Journal Sleep, 27, 726-731.

Abdel-Khalek, A. M.(2006). Prevalence of insomnia complaints and its consequences in Kuwaiti college students. Sleep and Hypnosis: An International Journal of Sleep, Dream, and H ypnosis,8, 54-60.

Abdel-Khalek, A. M.(2008).The development and validation of the Arabic Scale of Insomnia (ASI).Slep and $\mathrm{H}$ ypnosis, 10, 3 - 10.

Abdel-Khalek, A. M., \& Alansari, B. M. (2004). Gender differences in anxiety among undergraduates from ten Arab countries. Social Behavior and Personality, 32,649-655.

Abe, $Y ., \&$ Germain, A. (2012). Insomnia and its correlates: Current concepts, epidemiology, pathophysiology and future remarks. In Jay Maddock (Ed.), Public health - methodology, environmental and systems issues (pp. 387418).http:/ / www. intechopen.com/ books/ public-healthmethodology-environmental-and-systemsissues/ insomniaand-its-correlates-currentconcepts-epidemiology-pathophysiology-andfuture remarks. Retrieved on 30. 04. 2013

American Psychiatric Association. (2000). Diagnostic and statistical manual of mental disorders (4th ed., text rev.). Washington, DC: Author.

Bakr, I. M., Abou El Ezz, N. F., AbdElaziz, K. M.,Khater, M. S., \& Fahim, H. I. (2011). Prevalence of insomnia in elderly living in geriatric homes in Cairo. The Egyptian Journal of Community M edicine. 29(5), 53-65.

Buysse, D. J. (2008). Assessing insomnia in epidemiological studies: What do we need? Slep and Hypnosis: An International Journal of Sleep, D ream, and Hypnosis, 10, 1-2.

Dohnt, H., Gradisar, M., \& Short, M. A. (2012). Insomnia and its symptoms in adolescents: Comparing DSM-IV and ICSD-II diagnostic criteria. Journal of Clinical Sleep M edicine, 8, 295299.

Grossman, M., \& Wood, W. (1993). Sex differences in intensity of emotional experience: A social role interpretation. Journal of Personality and Social Psychology, 65, 1010-1022.

Gur, R. C., Gunning-Dixon, F., Bilker, W. B., \&Gur, R. E. (2002). Sex differences in temporo-limbic and frontal brain volumes of healthy adults. Cerebral Cortex, 12, 998-1003.

Hudson, T. (2004, A pril). Women's health update. Townsend letter for doctors and patients. http:/ / www.encognitive.com/ files/Insomnia

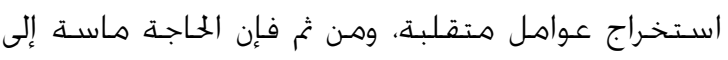

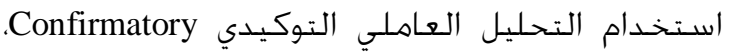

$$
\begin{aligned}
& \text { وذلك منوط بدراسـة مستقلة. }
\end{aligned}
$$

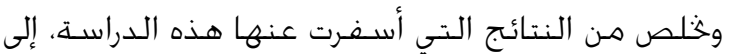

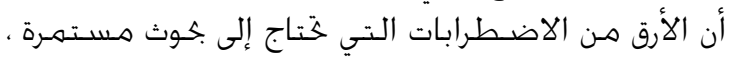

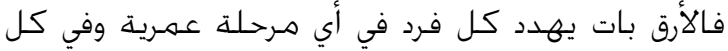

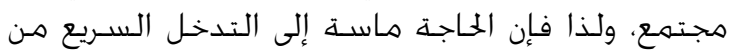

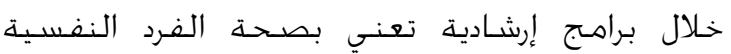

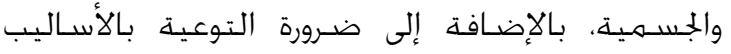

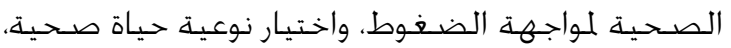

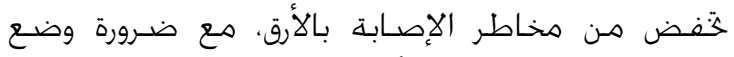

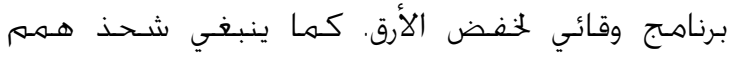

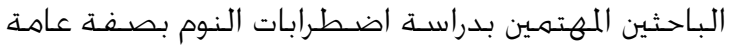

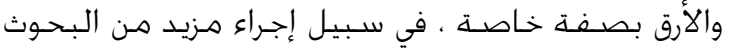

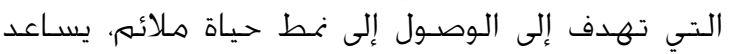

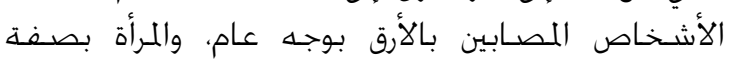

$$
\begin{aligned}
& \text { خاصدة على مواجهة تلك المتغيرات الحادثة في الحادياة }
\end{aligned}
$$

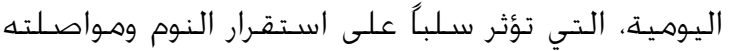

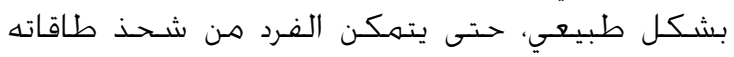

$$
\begin{aligned}
& \text { لـداوهة نشاطه في صباح اليوم التالي. } \\
& \text { المراجع }
\end{aligned}
$$

\section{References}

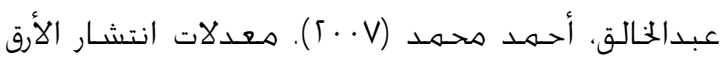

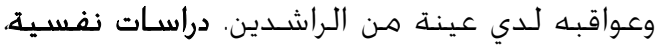

$$
\begin{aligned}
& . \Gamma V \cdot-\Gamma \leq V . I V
\end{aligned}
$$


\%20and\%20Sleep\%20Disorders\%20in\%20Wom en. pdf Retrieved on 24. 03. 2013.

Kaneita, Y.,Ohida, T., Osaki, Y., Tanihata, T.,Minowa, M., Suzuki K., Wada, K., Kanda, H., \& Hayashi, K. (2006). Insomnia among Japanese adolescents: A nationwide representative survey. Sleep, 29, 1543-1550.

Kline, P. (2000). H andbook of psychological testing (2nd ed.). London: Routledge.

Krystal, A. D. (2003). Insomnia in women. Clinical Cornerstones, 5 (3), 41-50.

Léger, D., Guilleminault, C., Dreyfus, J. P., Delahaye, C., \& Paillard, M. (2000). Prevalence of insomnia in a survey of 12778 adults in France. J ournal of Slep Research, 9, 35-42.

Li, R., Wing, Y., Ho, S., \& Fong, S. (2002). Gender differences in insomnia-A study in the Hong Kong Chinese population. Journal of Psychosomatic Research, 53,601-609.

Lopes, C., Robaina, J. R., \& Rotenberg, L. (2012) Epidemiology of insomnia: Prevalence and risk factors. www. intechopen. com Retrieved on 22. 03.2013

Mai, E., \& Buysse, D. J. (2008). Insomnia: Prevalence, impact, pathogenesis, differential diagnosis, and evaluation. Sleep M edicine Clinics, 3, 167-174.

Mydin, Y., Zahrim, N., \& Almashor, S. (2012). Correlates between insomnia, psychological distress and daytime sleepiness of Malaysian adults with symptoms of insomnia. Journal of Psychiatry, 13, 122-127.

National Sleep Foundation. (2005). Sleep in America poll 2005. http:// www. sleepfoundation. org/ content/ hottopics/ 2005 summary of findings. Retrieved on 22. 03. 2013

Nunnally, J. C. (1978). Psychometric theory (2nd ed.). New York: McGraw Hill.

Ohayon M. (1997). Prevalence of DSM IV diagnostic criteria and insomnia: Distinguishing insomnia related to mental disorders from sleep disorders.j ournal of Psychiatry Research, 31, 333346.

Ohayon, M. M. (2002). Epidemiology of insomnia: What we know and what we still need to learn. Slep M edicine, 6, 97-111.

Ohayon, M. M., \& Sagales, T. (2010). Prevalence of insomnia and sleep characteristics in the general population of Spain. Sleep M edicine, 11, 1010-1018.

Pallesen, S., Nordhus, I., Nielsen, G., Havik, O., Kvale, G., Johnsen, B., \& Skjøtskift, S. (2001).
Prevalence of insomnia in the adult Norwegian population. Sleep, 24, 771-779.

Roth, T. (2007). Insomnia: Definition, prevalence, etiology, and consequences. Journal of Sleep M edicine, 15, 7-10.

Roth, T., Krystal, A. D., \& Lieberman, J. A. (2007). Long-term issues in the treatment of sleep disorders. CN S Spectrums, 12, 1-14.

Schopenhauer, A. (2007). Counsels and maxims (T. Bailey Saunders, Trans.). New York, NY: Cosimo. (Original work published 1890).

Sheng, T. S. (2011). A study of prevalence of insomnia among University Tunkuy Abdul Rahman's students. MA thesis, Faculty of Creative Industries, University Tunku Abdul Rahman.

Sing, C. Y., \& Wong, W. S. (2010). Prevalence of insomnia and its psychosocial correlates among college students in Hong Kong. Journal of A merican College $\mathrm{H}$ ealth, 59, 174-182.

Stevens, J. (1995). A pplied multivariate statistics for the social sciences (3rd ed.) New Jersey: Lawrence Erlbaum Associates.

Talbot, L. S., \& Harvey, A. G. (2010). Psychological models of insomnia. In M. Sateia \& D. Buysse (Eds.). Insomnia: Diagnosis and treatment. (pp. 42-49). New York: Routledge, Medical Psychiatry Series. 